\title{
Mechanisms of cardiac arrhythmias and sudden death in transgenic rabbits with long QT syndrome
}

\author{
Michael Brunner, ${ }^{1}$ Xuwen Peng, ${ }^{2}$ Gong Xin Liu, ${ }^{3}$ Xiao-Qin Ren, ${ }^{3}$ Ohad Ziv, ${ }^{3}$ Bum-Rak Choi, ${ }^{3}$
} Rajesh Mathur, ${ }^{1}$ Mohammed Hajjiri, ${ }^{3}$ Katja E. Odening, ${ }^{3}$ Eric Steinberg, ${ }^{2}$ Eduardo J. Folco, ${ }^{4}$ Ekatherini Pringa, ${ }^{3}$ Jason Centracchio, ${ }^{3}$ Roland R. Macharzina, ${ }^{1}$ Tammy Donahay, ${ }^{3}$ Lorraine Schofield, ${ }^{3}$ Naveed Rana, ${ }^{3}$ Malcolm Kirk, ${ }^{3}$ Gary F. Mitchell, ${ }^{5}$ Athena Poppas, ${ }^{3}$ Manfred Zehender, ${ }^{1}$ and Gideon Koren ${ }^{3}$

\author{
${ }^{1}$ Innere Medizin III — Kardiologie und Angiologie, Universitätsklinikum Freiburg, Freiburg, Germany. \\ ${ }^{2}$ Department of Comparative Medicine, Pennsylvania State University College of Medicine, Hershey, Pennsylvania, USA. \\ ${ }^{3}$ Cardiovascular Research Center, Division of Cardiology, Department of Medicine, Rhode Island Hospital, \\ Warren Alpert Medical School of Brown University, Providence, Rhode Island, USA. ${ }^{4}$ Cardiovascular Division, \\ Brigham and Women's Hospital, Harvard Medical School, Boston, USA. ${ }^{5}$ Cardiovascular Engineering Inc., Waltham, Massachusetts, USA.
}

\begin{abstract}
Long QT syndrome (LQTS) is a heritable disease associated with ECG QT interval prolongation, ventricular tachycardia, and sudden cardiac death in young patients. Among genotyped individuals, mutations in genes encoding repolarizing $\mathrm{K}^{+}$channels (LQT1:KCNQ1; LQT2:KCNH2) are present in approximately $90 \%$ of affected individuals. Expression of pore mutants of the human genes KCNQ1 (KvLQT1-Y315S) and KCNH2 (HERG-G628S) in the rabbit heart produced transgenic rabbits with a long QT phenotype. Prolongations of QT intervals and action potential durations were due to the elimination of $I_{K s}$ and $I_{K r}$ currents in cardiomyocytes. LQT2 rabbits showed a high incidence of spontaneous sudden cardiac death $(>50 \%$ at 1 year) due to polymorphic ventricular tachycardia. Optical mapping revealed increased spatial dispersion of repolarization underlying the arrhythmias. Both transgenes caused downregulation of the remaining complementary $I_{K r}$ and $I_{K s}$ without affecting the steady state levels of the native polypeptides. Thus, the elimination of 1 repolarizing current was associated with downregulation of the reciprocal repolarizing current rather than with the compensatory upregulation observed previously in LQTS mouse models. This suggests that mutant KvLQT1 and HERG interacted with the reciprocal wild-type $\alpha$ subunits of rabbit ERG and KvLQT1, respectively. These results have implications for understanding the nature and heterogeneity of cardiac arrhythmias and sudden cardiac death.
\end{abstract}

\section{Introduction}

The long QT syndrome (LQTS) is a familial, usually autosomal dominant disease, characterized by prolongation of the QT interval in the surface ECG, spontaneous polymorphic ventricular tachycardia (VT, often termed torsade de pointes [TdP]), and sudden cardiac death in young patients (1-3). At least 9 different forms of the disease have been described so far, but in the vast majority of successfully genotyped patients, the underlying causes are mutations in the voltage-gated $\mathrm{K}^{+}$channels, either in the KQT-like subfamily, member 1 (KCNQ1), causing LQT1, or in the voltage-gated $\mathrm{K}^{+}$channel, subfamily $\mathrm{H}$, member $2(\mathrm{KCNH} 2)$, causing LQT2, and a dominant negative mechanism has been suggested in many of these mutations (4-7). In these patients, ventricular arrhythmias and sudden death are often triggered by emotional stress and/or physical exercise (e.g., swimming). In female LQTS patients, an increase in the incidence of arrhythmias has been reported with

Nonstandard abbreviations used: APD, action potential duration; EAD, early afterdepolarization; $I_{K 1}$, inward rectifier current; $I_{K r}$, rapidly activating delayed rectifier $\mathrm{K}^{+}$current; $I_{K s}$, slowly activating delayed rectifier $\mathrm{K}^{+}$current; $I_{t o}$, transient outward current; LMC, littermate control; LQT1, LQTS, type 1; LQTS, long QT syndrome; $\beta$-MyHC, $\beta$-myosin heavy chain; NZW, New Zealand white; QTexp, genotype-specific expected QT interval at a given heart rate; SCD, sudden cardiac death; VF, ventricular fibrillation; VT, ventricular tachycardia

Conflict of interest: The authors have declared that no conflict of interest exists. Citation for this article: J. Clin. Invest. 118:2246-2259 (2008). doi:10.1172/JCI33578. menses and during the first months postpartum $(2,8)$. Besides symptomatic treatment with beta blockers, which reduces the frequency of arrhythmias, and the implantation of automated defibrillators to terminate the fatal arrhythmias, no causal therapy is currently available $(2,9)$.

In experimental studies, transgenic mouse models of the LQTS (10-14) have shown at the cellular level that dominant negative mutations in genes coding for repolarizing $\mathrm{K}^{+}$channels lead to a prolongation of the duration of the action potential, with a variable incidence of early afterdepolarizations, regional electrical heterogeneities, and reentrant arrhythmias (10,15-18). Moreover, the phenotype of mice expressing pore mutant dominant negative transgenes in the heart was similar to that of the knockout of the targeted channel $(10,15-18)$. Of note, the downregulation of the $\mathrm{K}^{+}$currents was associated with electrical remodeling characterized by upregulation of other $\mathrm{K}^{+}$currents $(14,16,17)$. In the mouse, however, the main repolarizing currents are carried by different channels compared with humans, which limits the applicability of studies in the mouse to human patients (19). In contrast, the rabbit heart bears marked similarity to the human heart (20), and the same $\mathrm{K}^{+}$currents - namely the rapidly activating component $\left(I_{K r}\right)$ and the slowly activating component $\left(I_{K s}\right)$ - determine the repolarization of the action potential. Thus, the rabbit represents a more physiologically relevant model system to study diseases affecting these channels. 
A

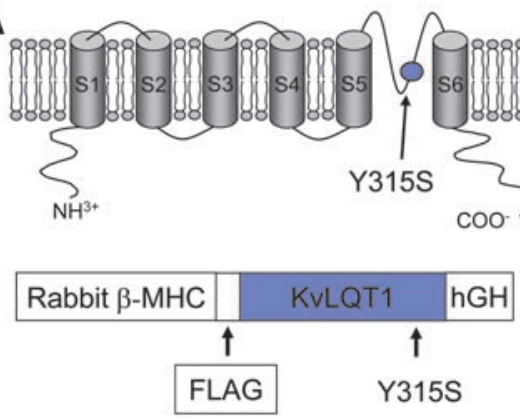

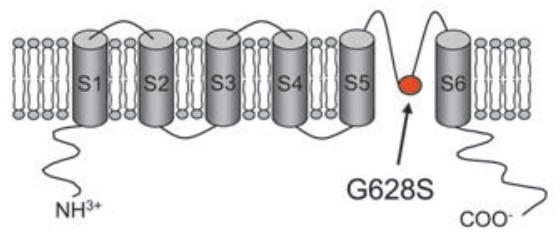

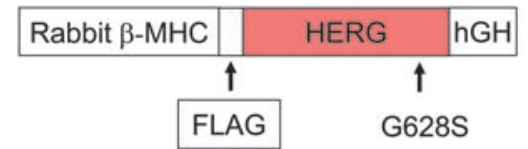

B
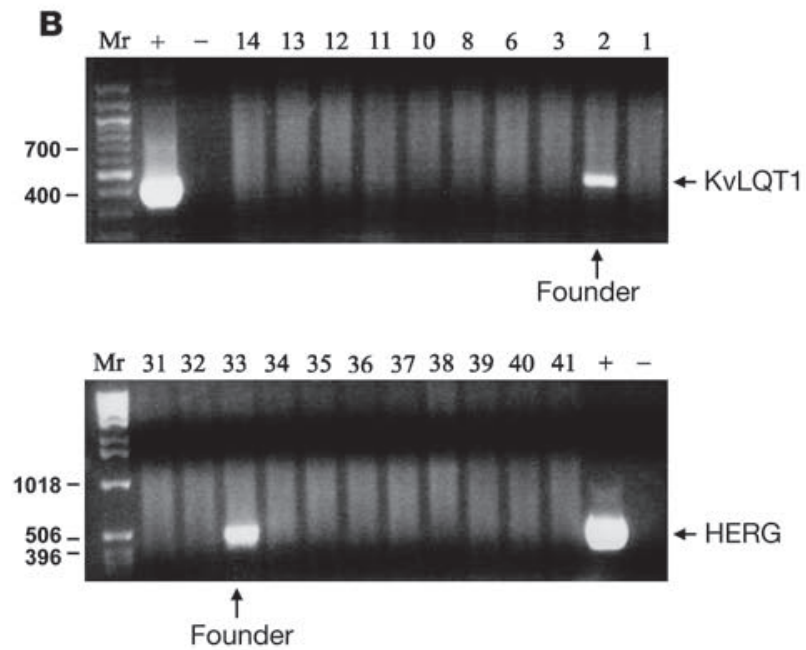

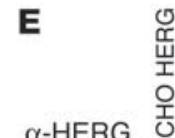
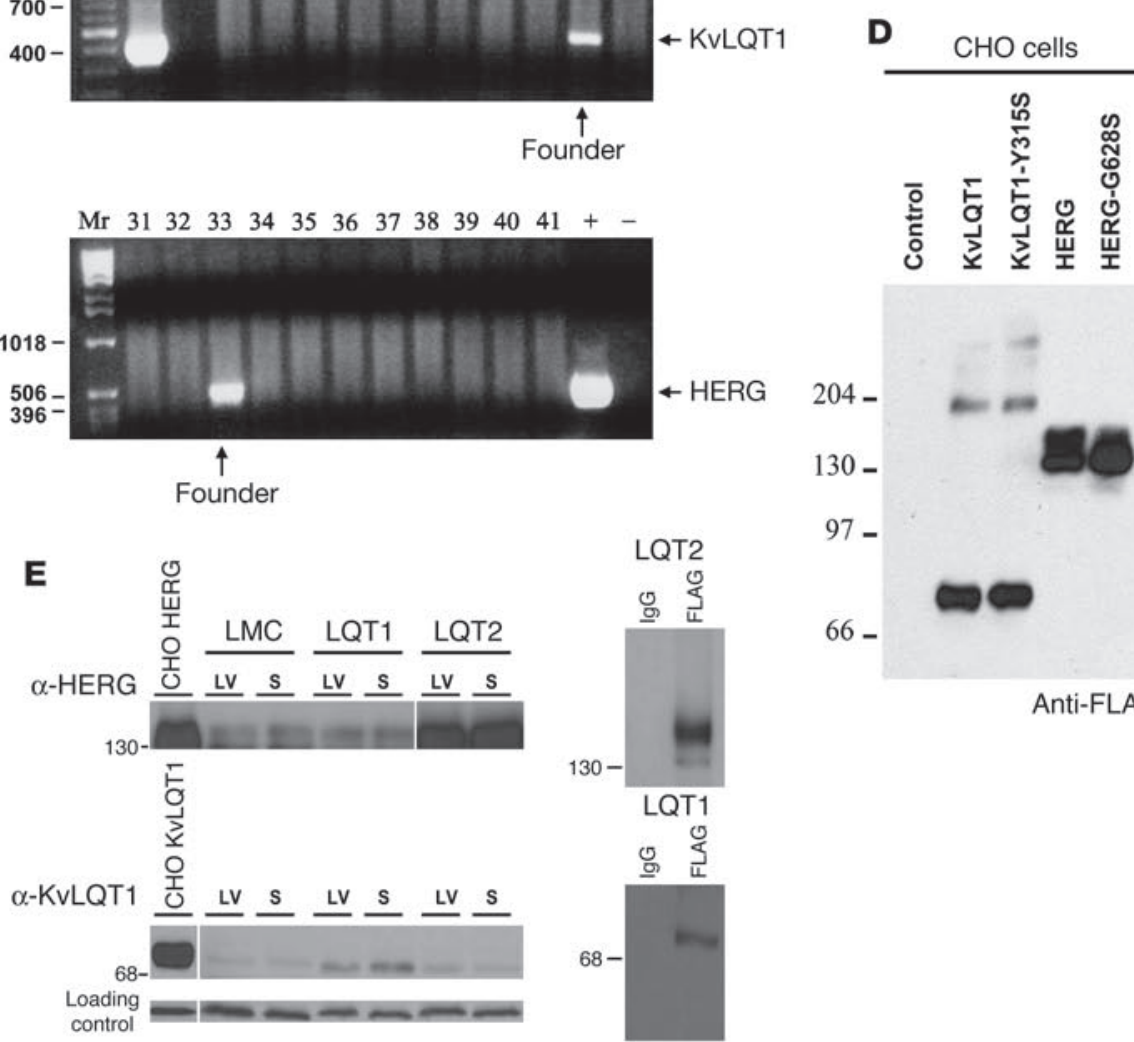

c
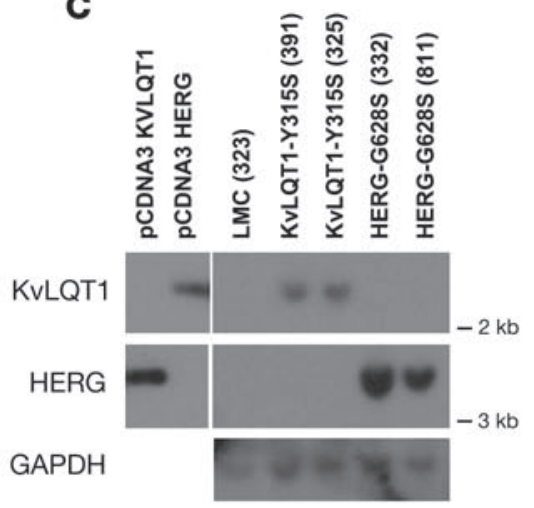

Rabbit heart input

Rabbit heart IP
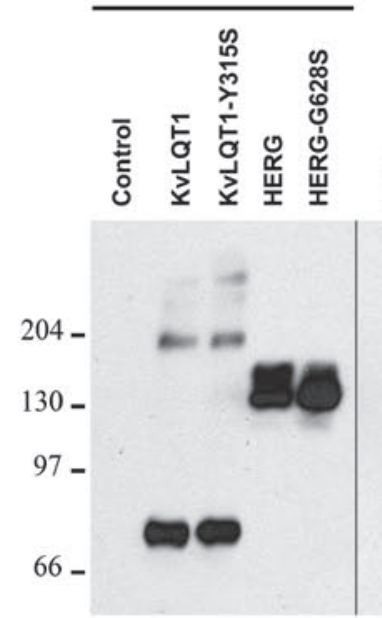

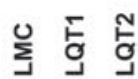
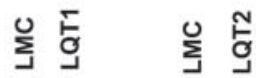

Anti-FLAG-IB
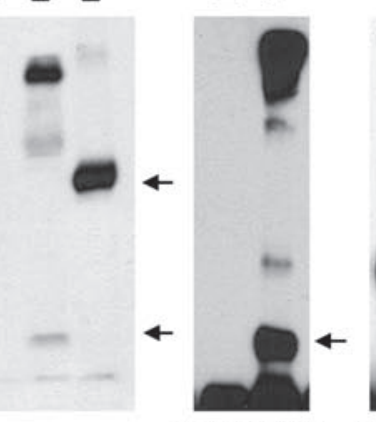

Anti-Kv

IB

IB

\section{Figure 1}

Transgenic constructs and expression studies. (A) Schematic drawings of the mutations (top) in KvLQT1 (left) and HERG (right) polypeptides and transgenic constructs (bottom). (B) PCR of genomic DNA of the founders: + and - denote positive control (constructs) and negative control. Numbers correspond to animals. Rabbits 2 (for KvLQT1) and 33 (HERG) tested positive. (C) Southern blot analyses of genomic DNA. Numbers in brackets indicate rabbit numbers. The sizes of the inserts incorporated into the rabbit genome (right panel) were identical to those of the plasmids (left panel). (D) Left panel shows Western blots of membrane lysates of CHO cells transfected with empty vector (control), KVLQT1, KvLQT1-Y315S, HERG, and HERG-G628S, and heart lysates from LMC, LQT1, and LQT2. Right panels show IP with anti-FLAG antibody of LMC, LQT1 (KvLQT1-Y315S), and LQT2 (HERG-G628S) crude heart lysates probed with anti-HERG and anti-KvLQT1 antibodies, respectively. The apparent molecular weight is $75 \mathrm{kDa}$ for KvLQT1 and $135 \mathrm{kDa}$ and $155 \mathrm{kDa}$ for HERG. (E) Crude heart membranes were prepared from sections (LV and septum [S]) of LMC, LQT1, and LQT2. $200 \mu \mathrm{g}$ samples were immunoblotted with polyclonal HERG antibody (top) and monoclonal KvLQT1 antibody (bottom). Crude membranes from CHO cells transfected with HERG and KvLQT1 cDNA served as positive controls. Anti-HERG antibody reacted with a 155-kDa polypeptide representing the endogenous RERG expression in LMC and LQT1 hearts. The antiKVLQT1 mAb detected a 75-kDa band representing the endogenous rabbit KvLQT1 channel polypeptides in LMC and LQT2 hearts. Upper right panel shows crude membranes from LQT2 or LQT1 rabbit hearts, which were reacted with either anti-FLAG mAb (right lane) or mouse IgG (left lane). Anti-HERG antibody detected a 155-kDa polypeptide, while IgG failed to precipitate this peptide. Lower right panel shows anti-KvLQT1 $\mathrm{mAb}$, which reacted with a 75-kDa band while IgG failed to precipitate it. 
A

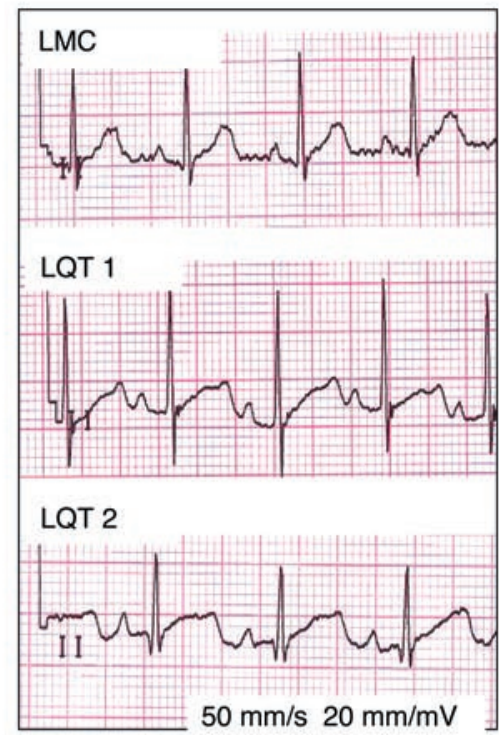

B

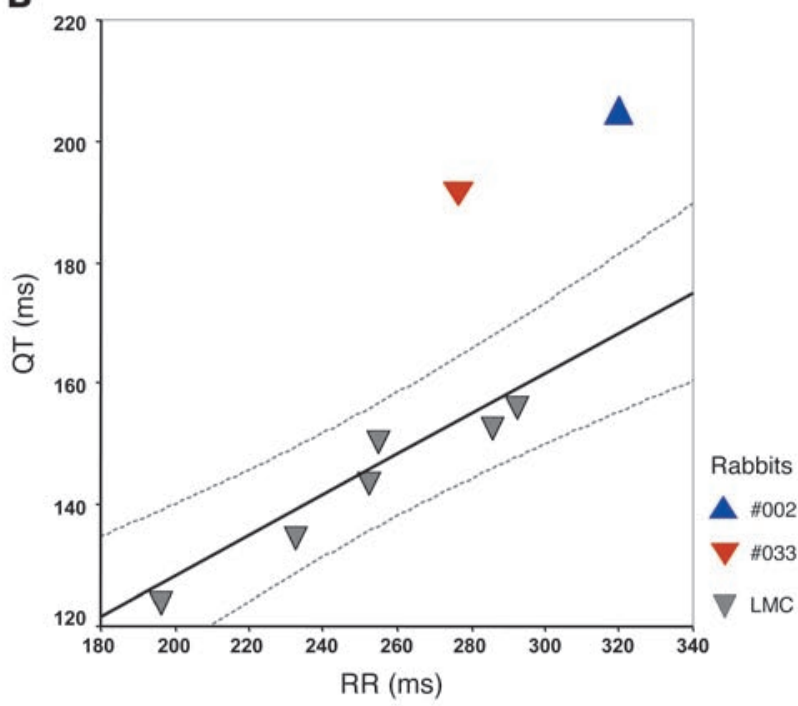

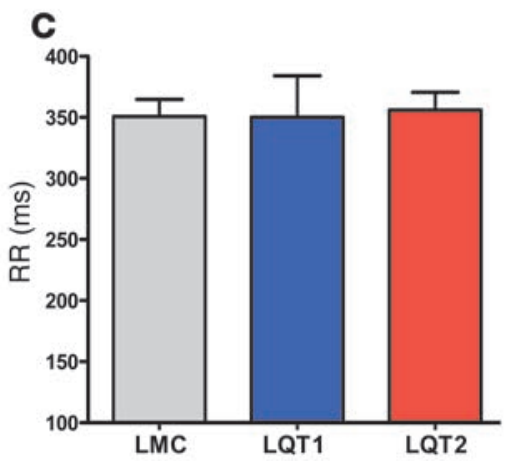
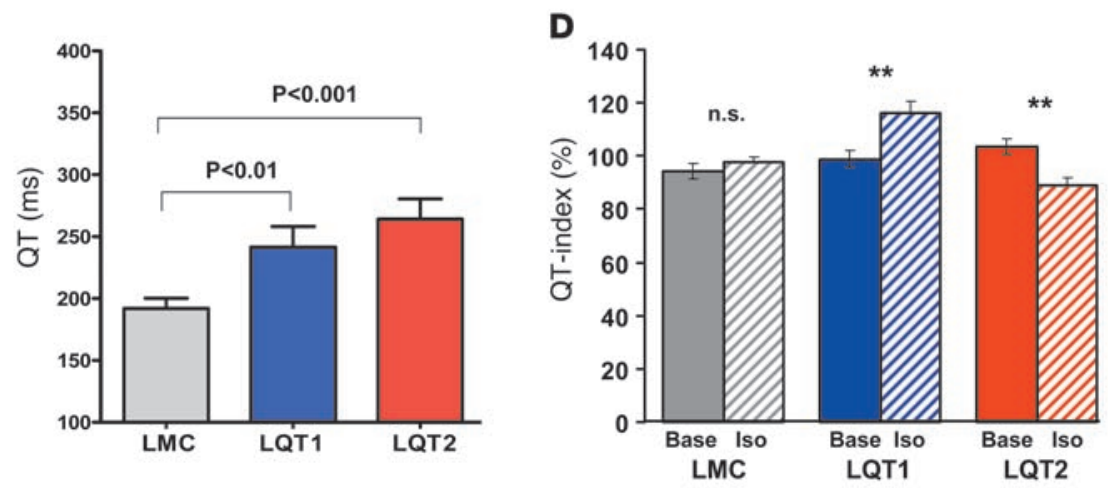

Figure 2

Phenotypic characterization in sedated animals. (A) Sample ECGs (lead II) of the founders and an LMC rabbit with midazolam sedation (2 mg/kg, i.m.). Note the markedly prolonged QT interval and the lack of an isoelectric T-P line in both transgenic rabbits. (B) QT/RR relationship (mean of all 12 leads per animal) under midazolam sedation in the 2 founder rabbits and 6 LMCs. Dotted lines denote the $95 \%$ confidence intervals of the linear regression derived from the LMCs. (C) RR and QT intervals (mean of 12-lead surface ECG per animal) in ketamine/xylazine-sedated male rabbits ( $n=13$ LMC, 9 LQT1, and 10 LQT2 animals). (D) Effect of isoproterenol on QT index in isoflurane-sedated LMC, LQT1, and LQT2 rabbits. Solid bars denote baseline (base); hatched bars denote isoproterenol (Iso). ${ }^{* \star} P<0.01$.

Here we show that expression of pore mutants of the human genes KCNQ1 (KvLQT1-Y315S) and KCNH2 (HERG-G628S) in the rabbit heart under the control of the rabbit $\beta$-myosin heavy chain ( $\beta$-MyHC) promoter produced LQT1 and LQT2 phenotypes in the rabbits, respectively. Characterization of the rabbits revealed that prolongations of the QT interval and action potential duration at $90 \%$ repolarization $\left(\mathrm{APD}_{90}\right)$ were due to the elimination of $I_{K s}$ and $I_{K r}$ currents, respectively. Only the LQT2 phenotype was associated with sudden cardiac death due to polymorphic VTs. Optical mapping studies revealed that spatial dispersion of repolarization underlies the reentrant arrhythmias in LQT2 rabbits. Of note, we also observed downregulation of the remaining complementary $I_{K r}$ and $I_{K s}$ currents, respectively, in cardiomyocytes derived from LQT1 and LQT2 rabbits as compared with those from littermate control (LMC) rabbits.
Thus, both rabbit models were associated with downregulation rather than with compensatory upregulation of the reciprocal repolarizing currents. These observations suggest that mutated KvLQT1 and HERG polypeptides might interact in vivo with the corresponding WT $\alpha$ subunits of RERG and rabbit KvLQT1, respectively.

\section{Results}

Creation of transgenic LQT1 and LQT2 rabbits. To generate transgenic rabbits, the FLAG-tagged KvLQT1-Y315S (21) and HERG-G628S
Table 1

Baseline values of ECG parameters measured in sedated LMC, LQT1, and LQT2 rabbits

$\begin{array}{llccccc} & \mathbf{R R}(\mathbf{m s}) & \mathbf{P R}(\mathbf{m s}) & \mathbf{Q R S}(\mathbf{m s}) & \mathbf{Q T}_{\text {peak }}(\mathbf{m s}) & \mathbf{T}_{\text {peak }}-\mathbf{T}_{\text {end }}(\mathbf{m s}) & \mathbf{Q T}(\mathbf{m s}) \\ \text { LMC }(n=13) & 350.8 \pm 50.1 & 72.5 \pm 6.2 & 50.0 \pm 4.3 & 147.4 \pm 24.5 & 45.5 \pm 8.7 & 191.9 \pm 29.8 \\ \text { LQT1 }(n=9) & 350.0 \pm 102.0 & 72.2 \pm 4.4 & 47.8 \pm 4.4 & 194.0 \pm 40.1^{\mathrm{A}} & 46.9 \pm 19.2 & 241.4 \pm 50.3^{\mathrm{B}} \\ \text { LQT2 }(n=10) & 356.0 \pm 46.0 & 70.0 \pm 0.0 & 48.0 \pm 4.2 & 223.0 \pm 48.8^{\mathrm{C}} & 40.4 \pm 11.6 & 264.3 \pm 51.3^{\mathrm{C}}\end{array}$

AP $<0.05$, ${ }^{\mathrm{B} P}<0.01$ compared with LMC; $\mathrm{C} P<0.001$ compared with LMC. 

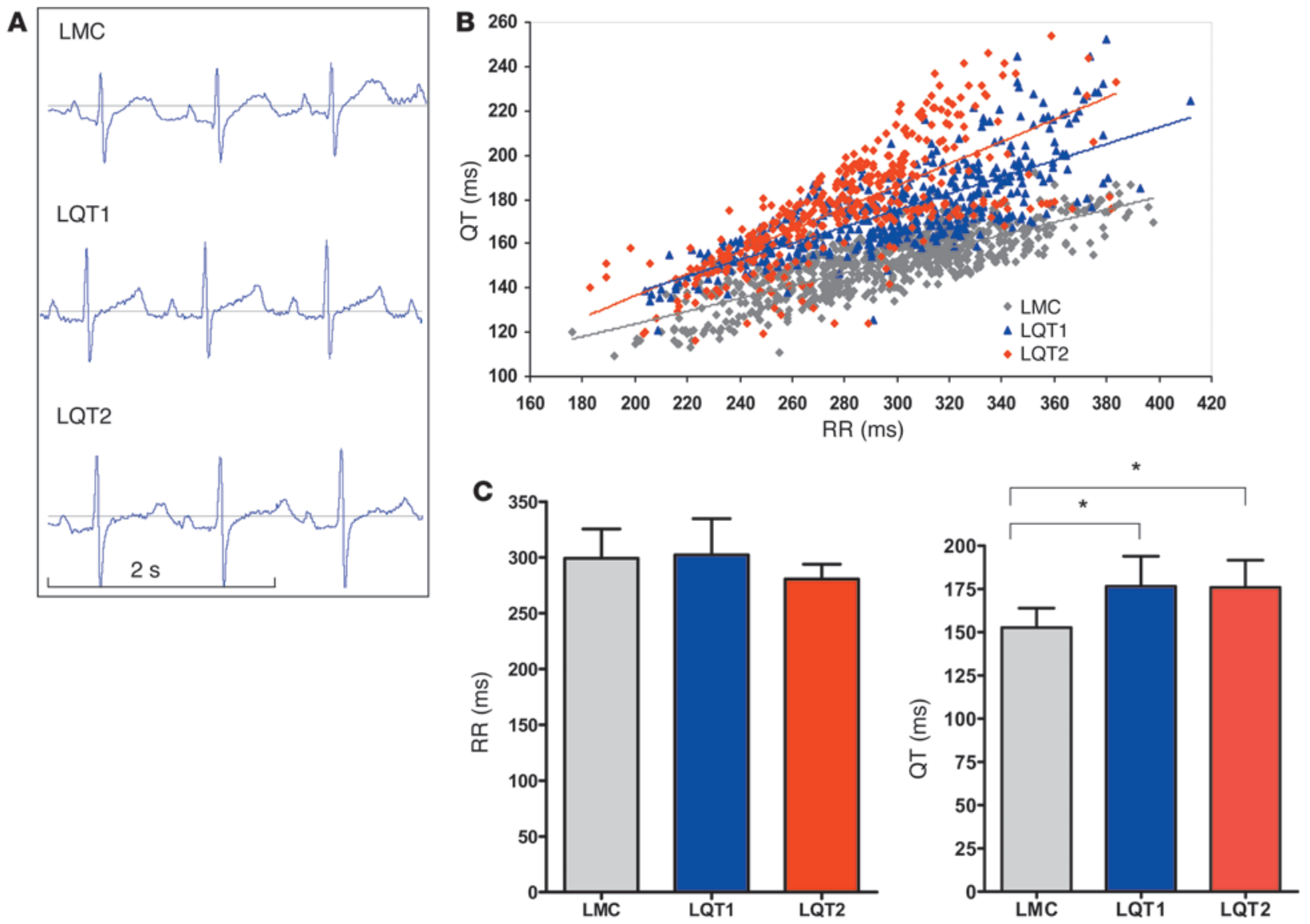

Figure 3

Phenotypic characterization in awake, free-moving animals. (A) Sample telemetric ECGs (lead II) of awake, free-moving male rabbits. (B) QT/RR relationship in awake, free-moving rabbits recorded approximately every 20 minutes for 24 hours in 11 LMC, 8 LQT1, and 6 LQT2 male rabbits. Lines indicate linear regression derived from the mean of all individual regression lines per genotype. (C) RR and QT intervals (mean of 72 telemetric measurements/animal during 24-hour monitoring) of awake, free-moving male rabbits. ${ }^{*} P<0.05$.

(5) cDNAs (kind gifts from J. Barhanin, Institut de Pharmacologie Moléculaire et Cellulaire, Valbonne, France, and M.C. Sanguinetti, University of Utah, Salt Lake City, Utah, USA) were first cloned under the control of the CMV promoter. The mutant cDNAs were then cloned under the control of rabbit $\beta$-MyHC promoters (22) (a kind gift of J. Robbins, Children's Hospital Research Foundation, Cincinnati, Ohio, USA) linked to the human growth hormone polyadenylation signal at the carboxyl terminus (Figure 1A). The $\beta$-MyHC-FLAG-KvLQT1-Y315S (LQT1) or $\beta$-MyHC-FLAG-HERGG628S (LQT2) insert was isolated and used to inject rabbit embryos. The offspring were screened by PCR (Figure 1B). Three male founders were identified: 2 were positive for the HERG-G628S (LQT2) transgene; 1 died at the age of 1 week, and 1 was positive for the KvLQT1-Y315S transgene (LQT1). Using Southern blots, the transgene copy number per diploid genome was estimated by comparing the intensity of the hybridization band with that of the control. LQT1 (KvLQT1-Y315S) rabbits ranged from 1-2 copies and LQT2 (HERG-G628S) ranged from 2 to 3 copies (Figure 1C). Expression studies in $\mathrm{CHO}$ cells demonstrated that both mutations coded for polypeptides that migrated similarly to the WT polypeptides (Figure 1D). Immunoblot analyses of crude membrane extracts derived from the hearts of these animals revealed that the corresponding transgene polypeptides were detectable with anti-FLAG antibody (Figure 1D). Immunoprecipitations of these polypeptides with anti-FLAG antibody followed by immunoblots with the specific antibodies (Figure 1D) revealed similar-sized reactive polypeptides. Of note, most of the KvLQT1-Y315S polypeptides aggregated and formed a large complex that migrated very slowly
Table 2

Effect of isoproterenol on sedated animals

\begin{tabular}{llcrccc}
\hline \multicolumn{3}{c}{ Baseline } & & \multicolumn{3}{c}{ Isoproterenol } \\
& QT $(\mathbf{m s})$ & $\mathbf{R R}(\mathbf{m s})$ & QT index & QT $(\mathbf{m s})$ & $\mathbf{R R}(\mathbf{m s})$ & QT-index \\
LMC & $229 \pm 31$ & $383 \pm 101$ & $94 \pm 3 \%$ & $201 \pm 14$ & $285 \pm 32$ & $97 \% \pm 2 \%$ \\
LQT1 & $222 \pm 39$ & $338 \pm 41$ & $99 \pm 3 \%$ & $221 \pm 34$ & $276 \pm 33$ & $116 \% \pm 4 \%{ }^{A}$ \\
LQT2 & $307 \pm 61$ & $337 \pm 62$ & $103 \pm 3 \%$ & $242 \pm 33$ & $304 \pm 47$ & $89 \% \pm 3 \%{ }^{B}$
\end{tabular}

${ }^{A} P=0.002$ compared with baseline; ${ }^{B} P<0.005$ compared with baseline. 
Table 3

Echocardiographic data

$\begin{array}{lcccccc} & \text { Age (months) } & \text { IVS }(\mathbf{m m}) & \text { PW }(\mathbf{m m}) & \text { LVD }(\mathbf{m m}) & \text { LVS (mm) } & \text { EF (\%) } \\ \text { LMC }(n=10) & 23.5 \pm 5.0 & 2.7 \pm 0.5 & 2.5 \pm 0.4 & 12.3 \pm 1.3 & 7.3 \pm 0.8 & 75.7 \pm 4.3 \\ \text { LQT1 }(n=8) & 27.2 \pm 4.2 & 2.8 \pm 0.5 & 2.7 \pm 0.5 & 12.0 \pm 1.2 & 7.3 \pm 1.0 & 74.0 \pm 4.8 \\ \text { LQT2 }(n=9) & 20.6 \pm 4.9^{A} & 2.4 \pm 0.2 & 2.3 \pm 0.2^{A} & 13.1 \pm 1.7 & 7.9 \pm 1.2 & 73.7 \pm 5.2\end{array}$

AP < 0.05 LQT1 vs. LQT2; all other comparison, $P=$ NS. EF, ejection fraction; IVS, intraventricular septum thickness; LVD, LV diastolic diameter; LVS, LV systolic diameter; PW, posterior wall thickness.

$175.9 \pm 15.78$ ms (ANOVA: $P<0.005$; LMC vs. LQT1, $P<0.01 ;$ LMC vs. LQT2, $P<0.05$ ) (Figure 3C).

Linear regression of the $\mathrm{QT} / \mathrm{RR}$ relation was performed for each animal, and the resulting regressions were averaged per genotype, resulting in the equation for QT intervals of LMCs: QT_LMC $=86+0.22 * \mathrm{RR}$. The slope of similar regressions for LQT animals was steeper in LQT1 (QT_LQT1 $=80+$ $0.32 * \mathrm{RR} ; P<0.05$ vs. LMCs) and more

(Figure 1D). Additional control experiments revealed that IgG did not IP these peptides (Figure 1E). We have investigated the level of expression of the endogenous channel polypeptides in crude membrane heart extracts. The results showed that the antibodies cross-reacted with the native peptides and that the steady-state level of KvLQT1 polypeptides expressed in the free wall and septum of LQT2 rabbits and RERG polypeptides in LQT1 rabbits was similar to those of LMC rabbits. Thus, the overexpression of the transgene polypeptides did not suppress the expression level of the native polypeptides (Figure 1E).

Phenotypic characterization. At the age of 4-5 months, the positive founders and age- and sex-matched littermates ( 2 male positive founders and 6 male controls) were characterized phenotypically with a 12-lead surface ECG. The transgenes caused a marked QT prolongation with an abnormal $\mathrm{T}$ wave morphology (Figure $2 \mathrm{~A}$ ) and an altered QT/RR relationship (Figure 2B). These founders were then crossbred with WT New Zealand white (NZW) (WT) rabbits, and the vertical transmission of the transgenes was confirmed by PCR of their genomic DNA extracted from ear biopsies of their offspring.

Using the offspring of the founders (F2-F3 generation), we recorded 12-lead surface ECGs in 13 LMC, 9 LQT1, and 10 LQT2 animals sedated with ketamine/xylazine. Baseline data of the major ECG parameters are presented in Table 1 and Figure $2 \mathrm{C}$. In transgenic rabbits, the $\mathrm{QT}_{\text {peak }}$ and total $\mathrm{QT}$ interval were significantly prolonged, with no significant difference in either $\mathrm{T}_{\text {peak }}-\mathrm{T}_{\text {end }}$ duration or the RR intervals or QRS and PR duration.

Awake, free-moving animals (11 LMC, 8 LQT1, and 6 LQT2 males) were monitored telemetrically after at least 3 weeks of recovery from the surgical implantation of the transmitter (Figure 3A). Figure $3 \mathrm{~B}$ displays the $\mathrm{QT} / \mathrm{RR}$ relationship of all measured $\mathrm{QT} / \mathrm{RR}$ pairs in these animals. The mean RR interval was $299.3 \pm 26.4 \mathrm{~ms}$ in LMC, $302.3 \pm 32.4 \mathrm{~ms}$ in LQT1, and $280.7 \pm 13.2 \mathrm{~ms}$ in LQT2 animals $(P=\mathrm{NS})$. The mean QT intervals were significantly different in LMC and transgenic animals: LMC, $152.7 \pm 11.2 \mathrm{~ms}$; LQT1, $176.6 \pm 17.3 \mathrm{~ms}$; and LQT2,

\section{Figure 4}

Histology of transgenic and LMC animals. Sample H\&E-stained histological sections of the middle of the LV free wall. Left panels, LMC; middle panels, LQT1 rabbit; right panels, LQT2 rabbit. Original magnification, $\times 10$ (top panels); $\times 20$ (middle panels); $\times 40$ (bottom panels). Scale bars: $10 \mu \mathrm{m}$. Boxes in the top row indicate areas of further magnification shown in the middle and bottom rows.
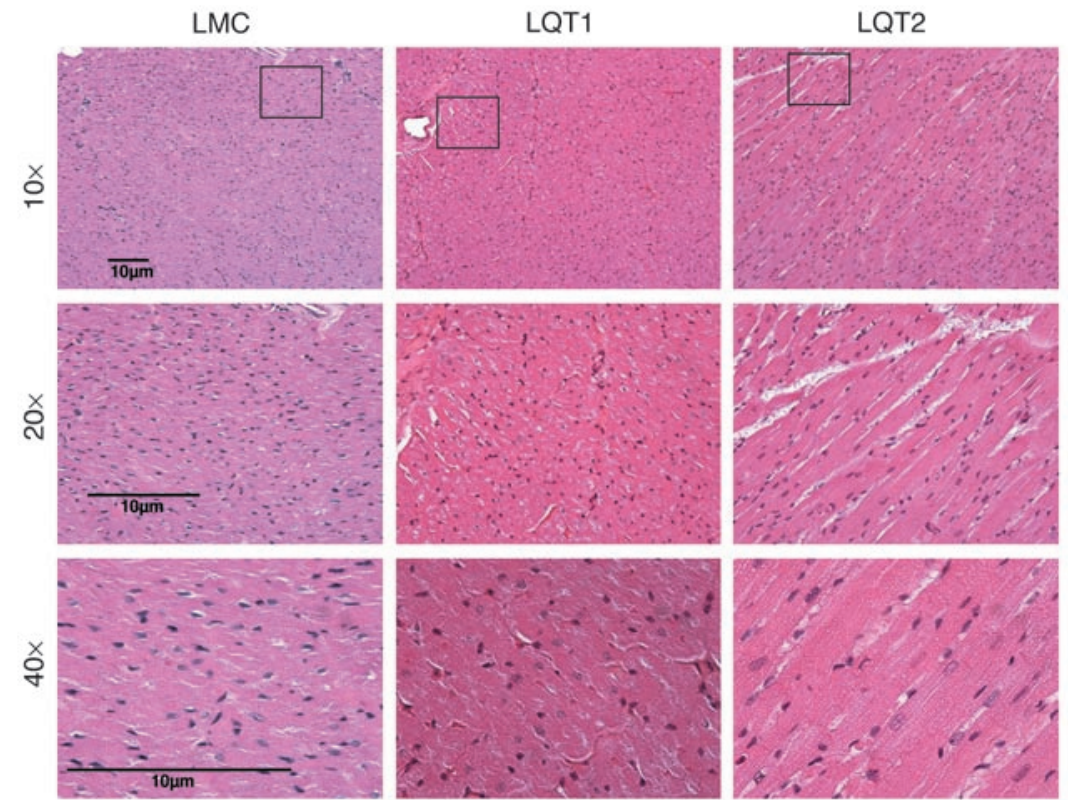
A

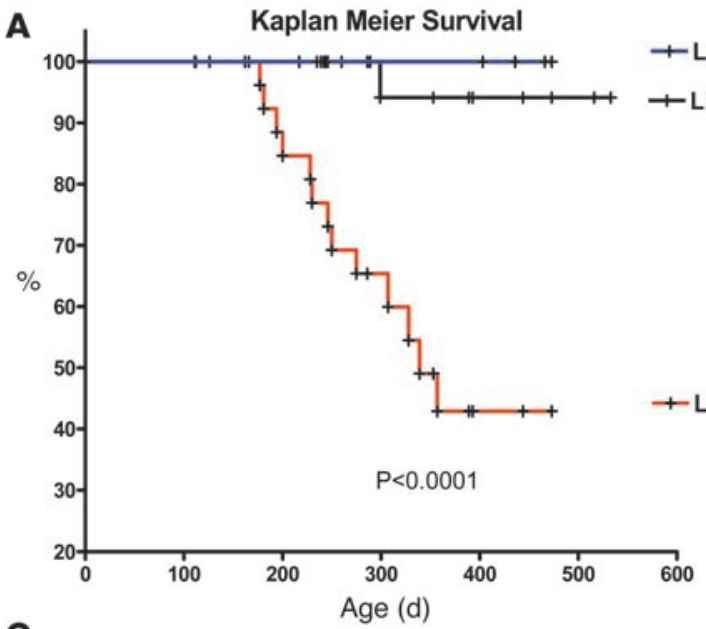

C

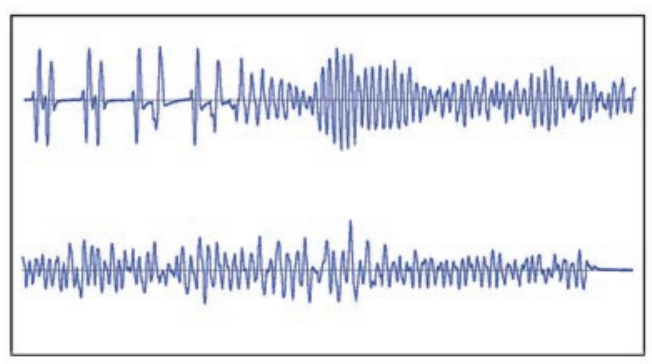

B

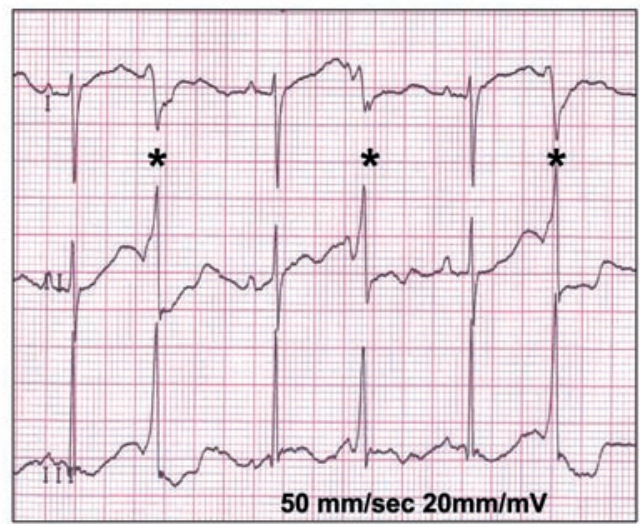

D

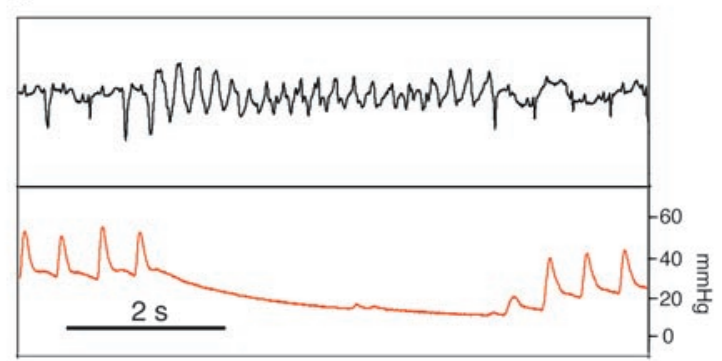

\section{Figure 5}

Sudden death and spontaneous arrhythmias. (A) Kaplan-Meier survival curve of 51 LMC, 26 LQT1, and 34 LQT2 rabbits. (B) Sample ventricular extrasystoles (bigeminy) with R-on-T phenomenon in the LQT2 founder rabbit during ECG (leads I, II, III) recording with midazolam sedation. Asterisks denote ventricular extrasystoles. This rabbit died suddenly approximately 2 weeks after this recording. (C) Telemetric recording of a polymorphic VT leading to the death of a LQT2 rabbit. The torsade is initiated by repetitive short-long-short sequences due to ventricular extrasystoles. (D) Spontaneous polymorphic tachycardia in a ketamine/xylazine-anesthetized rabbit. Top panel shows ECG lead II. Bottom panel shows simultaneous arterial pressure recorded from the ear artery.

(QTexp) under isoflurane $\left(I_{K s}\right.$ blocker): LMC: QTexp $=92+0.40$ * RR; LQT1: QTexp = $74+0.42 *$ RR; LQT2: QTexp = $76+0.65$ * RR. The QT index was calculated as follows: percentage of QT observed/QT expected. We observed a significant isoproterenolinduced prolongation of the heart-rate-corrected QT index in LQT1 rabbits. In contrast, in LQT2 rabbits, we observed a significant shortening of QT index (Figure 2D), demonstrating a differential pharmacogenomic effect of the drug in these LQT rabbits. Due to the length of the procedure, all rabbits were anesthetized with the $I_{K s}$ blocker isoflurane (27). Consequently, we observed a blunted response to isoproterenol in LMC rabbits without the expected QT shortening.

Echocardiography was performed in 8-10 rabbits from each group. LQT2 animals were younger than LQT1 animals $(20.6 \pm 4.9$ months vs. $27.2 \pm 4.2$ months; $P<0.05)$, but neither transgenic group was significantly different from LMC (23.5 \pm 5.0 months). No difference in LV ejection fraction, LV wall thickness, LV diameter, and intraventricular septum thickness was found in transgenic animals compared with LMC rabbits. However, the posterior wall in LQT2 animals was slightly thinner compared with LQT1 animals but not LMC animals, likely due to their younger age (Table 3). Minor valve insufficiencies of the tricuspid, pulmonary, and mitral valves were seen in 3-5 animals per group; no other abnormalities were detected.
Staining of LMC and transgenic hearts with H\&E revealed normal myocardium in all 3 groups without myofibrillary disarray, fibrosis, or other morphologic changes in the transgenic rabbit hearts (Figure 4).

Incidence of arrhythmias and sudden death in transgenic rabbits. We used the Kaplan-Meier method to estimate survival free of sudden death (defined as any death without an obvious noncardiac cause) of LMC and transgenic rabbits. Rabbits in this cohort did not undergo instrumentation or surgery, were handled only for routine animal care, and were mated to generate offspring. The survival of 26 LQT1 and 34 LQT2 rabbits was compared with that of 51 LMC rabbits, with an average follow-up of $288 \pm 126.8$ days for LMC animals, $340 \pm 104.6$ days for LQT1 animals, and $266 \pm 118$ days for LQT2 animals. One sudden death occurred in LMC controls vs. none in the LQT1 rabbits $(P=\mathrm{NS})$ vs. 14 deaths in the LQT2 group $(P<0.0001)$ (Figure $5 \mathrm{~A})$. No sex differences were seen in the mortality rates of the groups. Sudden death was precipitated in some animals by stress (mating and handling) or by lactation in females.

The reasons for sudden death were further defined by implanting ECG transmitters in an additional 10 LMC, 9 LQT1, and 7 LQT2 male rabbits and continuously monitoring the animals for arrhythmias: 2 of 7 LQT2 animals died of spontaneous polymorphic VT (Figure 5C) versus none of the LMC or LQT1 ani- 
A
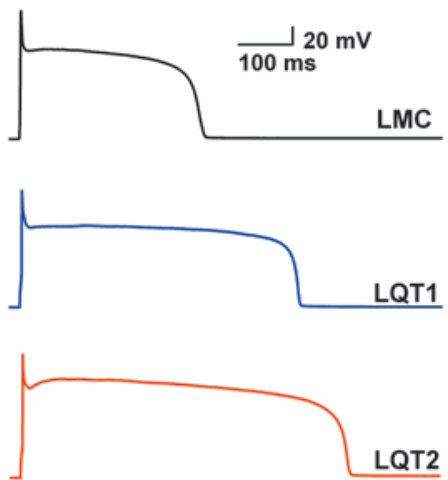

B

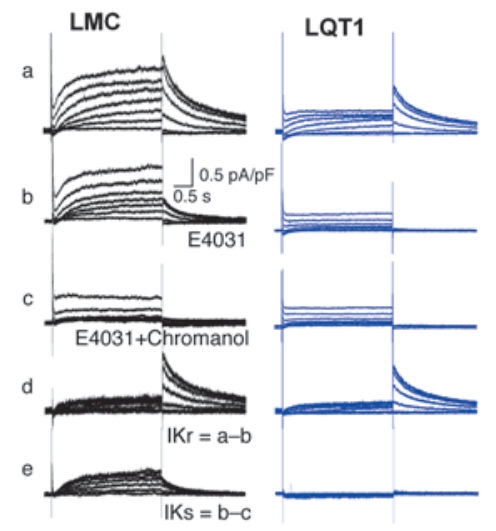

C
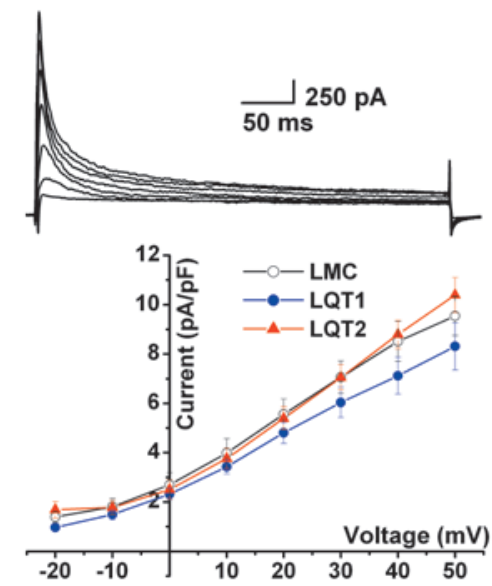
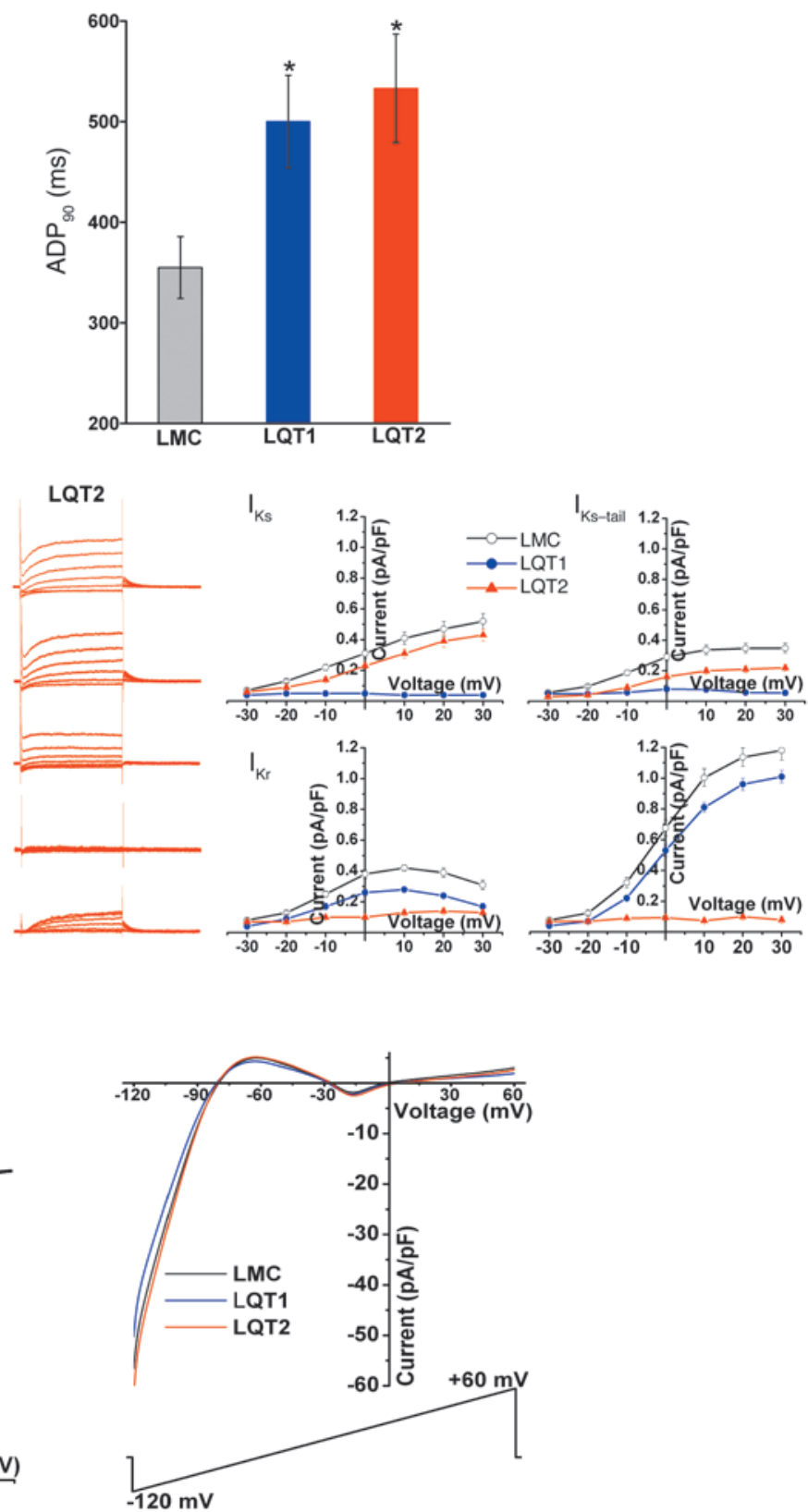

\section{Figure 6}

Cellular electrophysiology. (A) APD of rabbit ventricular myocytes. Left panel shows typical action potential recordings $(0.1 \mathrm{~Hz})$ from LMC, LQT1, and LQT2 rabbits. Right shows averaged APD (APD 90 , mean \pm SEM) of LMC (354.05 $\pm 30.07 \mathrm{~ms}, n=22)$, LQT1 (499.88 $\pm 45.71 \mathrm{~ms}$, $n=14)$, and LQT2 rabbits $(533.14 \pm 54.22 \mathrm{~ms}, n=14) ;{ }^{*} P<0.05$. (B) Isolation and quantification of $I_{k r}$ and $I_{K s}$. Left panel shows original recordings of control, LQT1, and LQT2 rabbits as indicated. After a recording without drugs (a), the cells were perfused with $5 \mu \mathrm{M}$ E-4031 (b) and $I_{K r}$ was defined as the E4031-sensitive current (d). Secondary to E4031 application, the cells were further perfused with $30 \mu \mathrm{M}$ chromanol 293B (c) and $I_{K s}$ was defined as chromanol-sensitive current (e). Right panels shows quantification of $I_{K r}$ and $I_{K_{s}}$. Current amplitudes measured at the end of repolarization $\left(I_{K_{s}}\right.$ or $\left.I_{K r}\right)$ and the peak of the tail $\left(I_{K s}\right.$ tail or $I_{K r}$ tail) were plotted against membrane voltages. All currents were normalized to cell capacitance. Open circles depict control myocytes ( $n=20$ from 6 rabbits), filled circles depict LQT1 myocytes ( $n=17$ from 5 rabbits), and filled triangles depict LQT2 myocytes ( $n=12$ from 3 rabbits). The downregulation of $I_{K r}$ (in LQT1) or $I_{K S}$ (in LQT2) was significant compared with controls $\left(P<0.05\right.$ by 2 -way ANOVA). (C) $I_{\text {to }}$ current and $I_{K 1}$ currents. Standard current-voltage relationship (IV curve) of $I_{\text {to }}$ (left panel) or quasi-IV curve of $I_{K 1}$ (right panel) revealed no significant differences in peak $I_{\text {to }}$ currents $(n=6-8)$ or $I_{K 1}$ currents (right, $n=10-12$ ) among LMC, LQT1, and LQT2 rabbits. 
A LMC

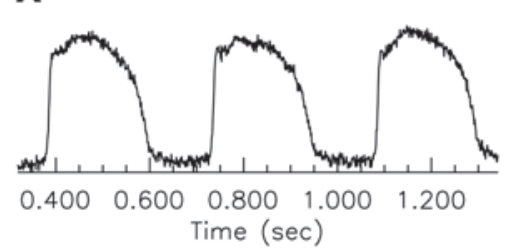

B LQT1

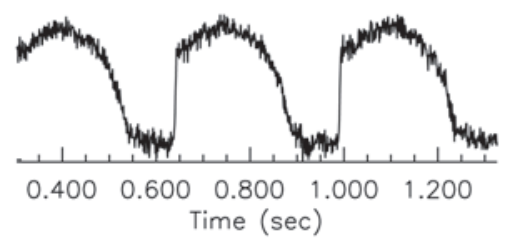

C LQT2

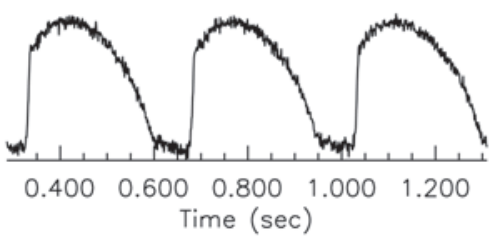

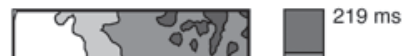
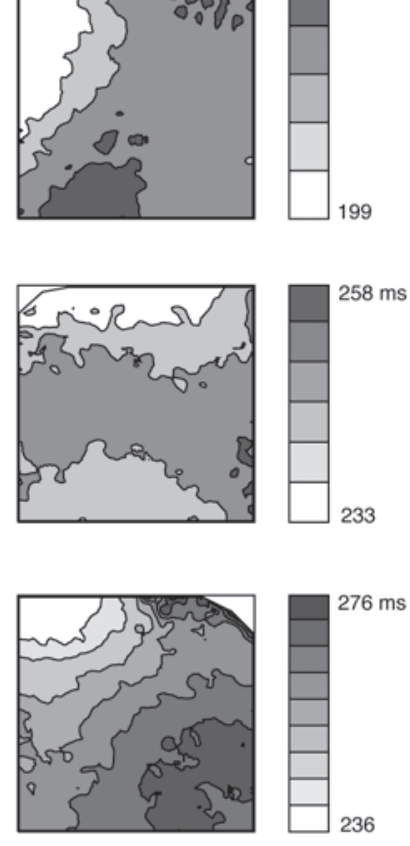

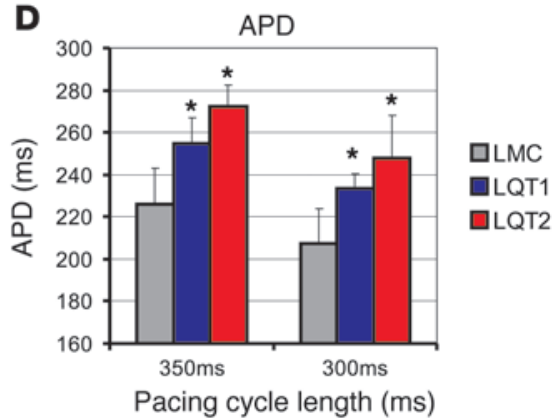

E

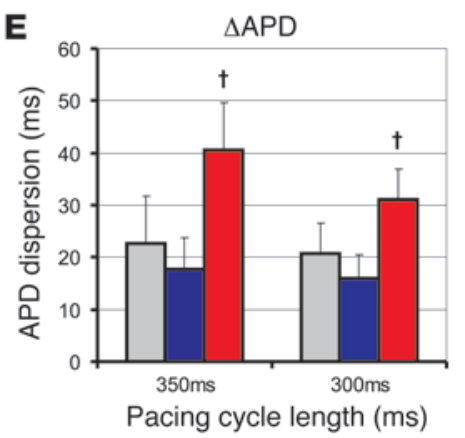

\section{Figure 7}

APD and APD dispersion in transgenic rabbits. (A-C) Typical raw data of action potential traces are shown in the left columns. APDs were measured as described in Methods and mapped in each group. Isochronal lines were drawn every 5 ms with lighter color representing shorter APD. (D) Mean APD in each group at basic cycle length of 350 and $300 \mathrm{~ms}$. LMC $(n=6)$, LQT1 $(n=3)$, and LQT2 rabbits $(n=4)$. LQT2 and LQT1 rabbits show statistically significant differences in APD compared with LMC; ${ }^{*} P<0.05$. (E) APD dispersion. APD dispersion was calculated by differences between $A P D_{\max }$ and $A P D_{\min }$. LQT2 rabbits show greater dispersion compared with $L M C$. ${ }^{\prime} P<0.05$.

mals during 4-6 weeks of monitoring. Additionally, spontaneous polymorphic VT was recorded in one LQT2 rabbit during anesthesia, leading to a dramatic drop in blood pressure (Figure $5 \mathrm{D})$ with prompt recovery after a spontaneous return to a normal sinus rhythm.

When analyzing 16 episodes of nonsustained and sustained polymorphic VT (in 3 male LQT2 rabbits and 4 female LQT2 rabbits), we found no significant differences in the heart rate directly prior to the onset of polymorphic VT episodes compared with baseline (before polymorphic VT: $197.5 \pm 58 / \mathrm{min}$, at baseline $218 \pm 39 / \mathrm{min}$ ), although in 3 of 16 polymorphic VT episodes, the preceding heart rate was significantly slower (84/min, 138/min, 126/min). In 1 episode, the polymorphic VT was preceded by an episode of AV 2:1 block. All 16 episodes started with an R-on-T phenomenon; in 11 of 16 , we observed short-long-short episodes initiating the polymorphic VT as has been described in human patients with acquired and congenital LQTS (28). All episodes of polymorphic VT were preceded by longer periods with multiple single premature ventricular contractions or short nonsustained VTs, and 5 episodes of polymorphic VT succeeded longer periods of ventricular bigeminy. These findings suggest that early afterdepolarizations (EADs) play a major role in the induction of arrhythmias.

Cellular electrophysiology of ventricular myocytes. Action potentials and various $\mathrm{K}^{+}$currents in myocytes isolated from the LV apex were investigated. The action potential was significantly longer in both LQT1 and LQT2 rabbit myocytes compared with the controls (Figure 6A). The averaged $\mathrm{APD}_{90}$ was $354.1 \pm 30.1 \mathrm{~ms}(n=22)$ in
LMC, $499.9 \pm 45.7 \mathrm{~ms}$ in LQT1 $(n=14)$, and $533.1 \pm 54.2 \mathrm{~ms}$ in LQT2 $(n=14)$ animals (both $P<0.05$ vs. LMC). To provide functional correlates with molecular targets in the 2 animal models, we first examined $I_{K r}$ and $I_{K s}$ currents in these myocytes. $I_{K s}$ currents were selectively abolished in cardiomyocytes derived from LQT1 hearts, whereas $I_{K r}$ currents were selectively abolished in LQT2 hearts (Figure 6B). Further characterization of $I_{K r}$ and $I_{K s}$ (Figure $4 \mathrm{~B})$ revealed that the current densities of $I_{K r}$ in LQT1 myocytes and of $I_{K s}$ in LQT2 myocytes were also decreased as compared with the LMC currents. At $+10 \mathrm{mV}$, for example, tail $I_{K s}$ in LQT2 was $0.31 \pm 0.03 \mathrm{pA} / \mathrm{pF}$ as compared with $0.41 \pm 0.04 \mathrm{pA} / \mathrm{pF}$ in LMCs $(P<0.05)$; tail $I_{K r}$ in LQT1 animals was $0.28 \pm 0.01 \mathrm{pA} / \mathrm{pF}$ as compared with $0.42 \pm 0.02 \mathrm{pA} / \mathrm{pF}$ in LMCs $(P<0.05)$. In contrast, the current densities of the other 2 prominent $\mathrm{K}^{+}$currents, the transient outward $\left(I_{t o}\right)$ and the inward rectifier $\left(I_{K 1}\right)$, did not differ among the LMC, LQT1, and LQT2 groups (Figure 6C).

Optical mapping of intact hearts. We next investigated the mechanism of arrhythmias in LQT rabbits using optical mapping of Langendorff-perfused hearts maintained at $37^{\circ} \mathrm{C}$. We found that the $\triangle \mathrm{APD}$ (defined as the absolute difference between maximum and minimum APD across the anterior epicardial surface) in LMCs was $23 \pm 9$ and in LQT1 rabbits was $18.0 \pm 6 \mathrm{~ms}$. In contrast, $\triangle \mathrm{APD}$ in LQT2 rabbits was $41 \pm 17 \mathrm{~ms}(P<0.05)$. The increase of APD dispersion in LQT2 rabbits suggests that nonuniformity of repolarization correlates with arrhythmogenesis. The APDs at different stimulation cycle lengths and the dispersion of repolarization $(\triangle \mathrm{APD})$ are summarized in Figure $7, \mathrm{D}$ and $\mathrm{E}$. 


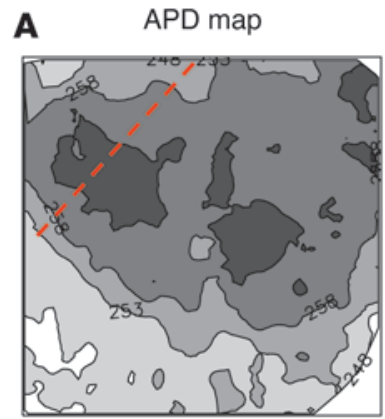

B

Initiation of VF

(1) (2) (3) (4) (5) (6) (7) (8)

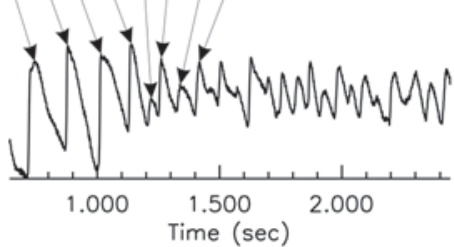

C Activation maps of initial VF beats

(1)

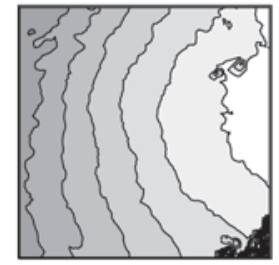

(5)

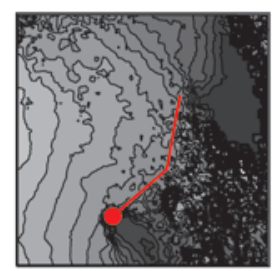

D $L M C$
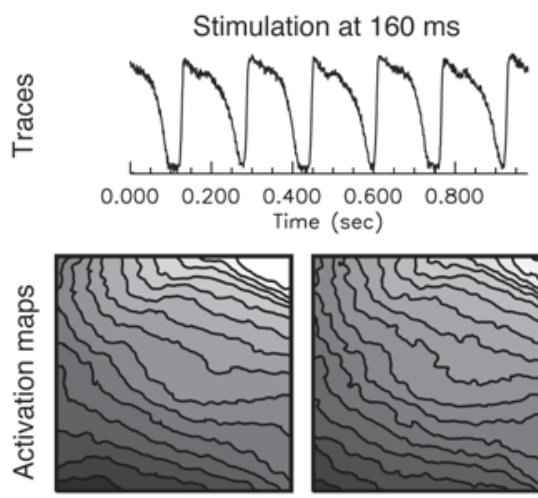

(2)

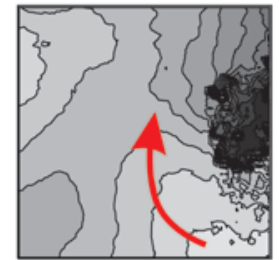

(6)
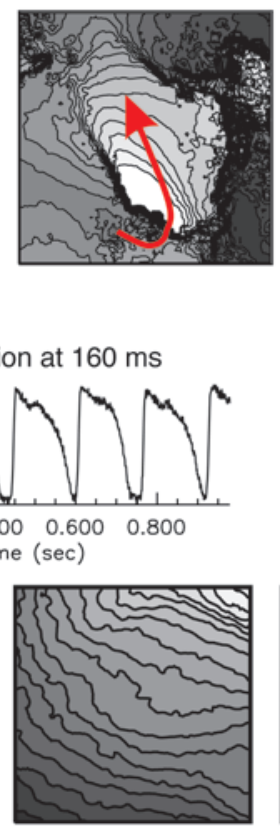

(3)

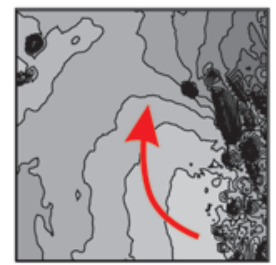

(7)

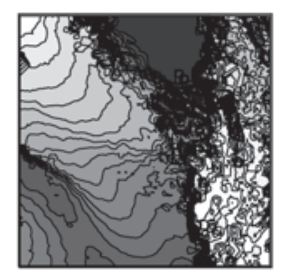

E LQT1
(4)

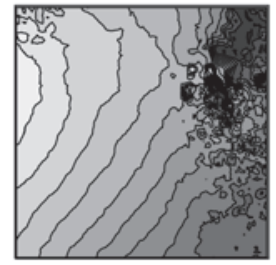

(8)

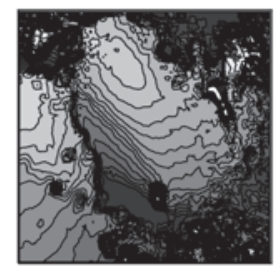

Stimulation at $240 \mathrm{~ms}$

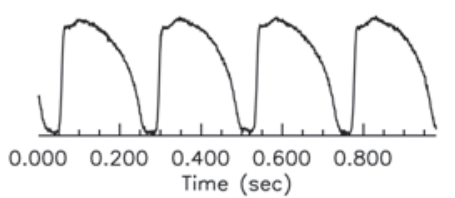

$40 \mathrm{~ms}$
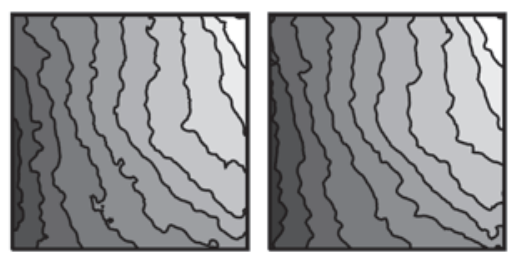

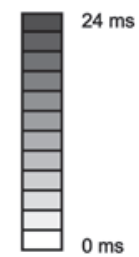

Figure 8

Activation maps of VF initiation in an LQT2 heart. (A) APD map. The red dotted line marks the interventricular septum. The APD map in LQT2 shows increased dispersion, mostly in the mid LV region. (B) Trace of action potentials during initial period of VF. (C) Series of activation maps marked in panel B. Isochronal lines are drawn every 2-ms interval, and lighter color represents earlier activation. Panel no. 1 shows activation pattern of the paced beat. The following beats (nos. 2 and 3) encounter conduction block where the APD is longer (see panel A). Therefore, the LV activated via the apical free wall where APD is shorter and tissue is recovered from the previous beat. The next activation (no. 4) appears from the RV and propagates toward the mid LV. A similar wave front (no. 5) encounters conduction block (red straight line) in the region where APD is longer and forms a rotation (no. 6), initiating VF (no. 7 and no. 8). This initiation highlights APD dispersion as an important mechanism in arrhythmia formation in this LQT2 model. (D and E) Traces and activation maps from LMC and LQT1 hearts. Traces and maps were taken at the shortest cycle length that did not cause 2:1 block. Both LMC and LQT1 showed uninterrupted conduction from the stimulation sites to the rest of the heart without rotation or conduction blocks. 
To test for inducibility of arrhythmias, hearts were stimulated from LV epicardium at a cycle length (CL) equal to $350 \mathrm{~ms}$ initially, and cycle lengths were reduced in 10-ms steps until either 2:1 block or VT or ventricular fibrillation (VF) occurred. Most LMCs $(n=6$ out of 7) and all LQT1 animals ( $n=4$ out of 4$)$ were not inducible by this method. However, VF was triggered by programmed stimulation in most LQT2 rabbits $(n=3$ out of $4 ; P<0.05)$. One LQT2 rabbit showed very long APDs and could not be stimulated at a basic cycle length shorter than $350 \mathrm{~ms}$. Pacing close to refractoriness induced VT/VF in LQT2 rabbits; however, induction of arrhythmia was not consistently seen at any specific paced heart rate. Examination of VF initiation showed that a premature beat during burst stimulation encountered refractoriness across an area of enhanced dispersion of APD, causing unidirectional block and consequently formation of reentry (see Figure 8 for details). In contrast, LMC and LQT1 animals showed smooth conduction without rotation or conduction blocks (Figure 8, D and E). Thus, APD dispersion is a major mechanism underlying LQT2-related arrhythmias (Figures 7 and 8).

\section{Discussion}

Transgenic and knockout mouse models have significantly improved our understanding of cardiac excitation (19), but because of significant differences in the length of the APD and the repolarization phase of the action potential of cardiomyocytes derived from mice and humans, none of the previously available mouse models fully emulates human LQTS (19). Unlike in the mouse heart, the rabbit action potential is remarkably similar to the human heart in that the same $\mathrm{K}^{+}$outward currents determine the dynamics of the repolarization phase of the action potential. Moreover, the fibrillatory rotors resemble those of the human heart (29). Here, we present the first transgenic rabbit models for the 2 most common human LQTS, types 1 and 2 . These rabbits were created by expressing dominant negative $\mathrm{K}^{+}$channel $\alpha$ subunits cloned from affected humans under the control of a rabbit $\beta$-MyHC (22, 30 ). We show that these mutated polypeptides consistently eliminated the currents encoded by their respective WT proteins, producing a dominant negative effect. Consequently, these constructs caused a significant prolongation of the APD by selectively eliminating $I_{K s}$ (in LQT1 animals) and $I_{K r}$ (in LQT2 animals). Furthermore, as opposed to the data from studies of various strains of genetically modified mice $(14,16)$, our data show no compensatory upregulation of other repolarizing currents in these rabbits.

Clinically, the elimination of $I_{K s}$ and $I_{K r}$ has differential effects: LQT1 rabbits show QT prolongation but neither spontaneous arrhythmias nor an increase in sudden death. LQT2 animals have a more pronounced QT prolongation at slow heart rates and show both spontaneous arrhythmias and a significant increase in sudden death after the age of approximately 200 days, consistent with the end of puberty in these animals. Additionally LQT2 females exhibit a high incidence of sudden death during lactation, an observation similar to the increased incidence of arrhythmias in women with the LQT2 syndrome postpartum (8).

The QT/RR relationship was highly individual among our transgenic and LMC rabbits during telemetric monitoring - similar to that in healthy human subjects (31). Therefore, we calculated individual regression lines and averaged these per group. We used linear regressions because nonlinear regressions did not yield markedly better correlations, an observation that has similarities to studies in humans (31). We are aware, however, that neither linear nor non- linear equations, such as Bazett formula, correct the QT interval properly to all ranges of heart rates, an issue that has been widely debated in the literature. Analysis of the QT/RR slope in the 2 transgenic lines and the controls revealed a pattern similar to that of the QT/RR slope as observed in affected humans with a steeper QT/RR relationship in LQT2 compared with LQT1 and LMC. This bears striking similarity to the results of studies in humans using Holter monitoring and exercise tests (32-34) in different populations.

Adult LQT2 patients have a higher risk of sudden death compared with LQT1 patients, and the risk is increased in those with a longer QT and in women $(9,35)$. LQT2 patients with a pore mutation have the highest risk of arrhythmic events (36). Here, we show that LQT2 animals with a mutation in the pore region (HERG-G628S) have a high incidence of spontaneous arrhythmias leading to sudden cardiac death (SCD). In congenital or acquired human LQTS, increased spatial dispersion of repolarization plays a major role in propagating and maintaining malignant arrhythmias $(37,38)$, and EADs due to prolonged APD have been assumed to trigger these arrhythmias. Experimental models in transgenic mice have shown increased apexto-base dispersion of repolarization underlying mouse arrhythmias $(17,39)$, and pharmacological LQT models in rabbits and dogs have reproduced this finding as transmural dispersion of repolarization in wedge preparations (40-43). Studies in experimental models (43, $44)$, in mathematical simulations $(45,46)$, and in affected humans with LQTS (47) have demonstrated the occurrence of phase 2 and 3 EADs in vitro, in silico, and in vivo, hinting toward $\mathrm{M}$ cells and/or Purkinje fibers as the origin of EADs $(44,46)$.

Here, we demonstrate an increased spatial dispersion of repolarization across the anterior epicardial surface as the electrical basis for spontaneous malignant arrhythmias in LQT2 animals. In contrast, LQT1 animals did not have increased dispersion, despite a similar degree of APD prolongation. Thus, lack of spatial dispersion of repolarization correlates with absence of spontaneous arrhythmias or sudden cardiac death. Moreover, further studies into the mechanism of VF induction revealed that programmed stimulation induced VF in LQT2 rabbits but not in LQT1 rabbits. Importantly, imaging of the initiation of the arrhythmias (Figure 8) demonstrated that when a premature beat encountered an area of prolonged APD, conduction block occurred, resulting in wave breakup and formation of reentry and VF. These events support the notion that spatial dispersion of repolarization plays a key role in the pathogenesis of VF in LQT2 rabbits.

Additionally, all documented episodes of SCD in these animals were induced by R-on-T extrasystoles, and most were preceded by short-long-short sequences, a common mechanism of initiating polymorphic VT in LQT patients (48). It has been suggested that the initiating extrasystoles in short-long-short sequences represent phase 3 EADs (48). Our optical mapping data do not address the mechanisms underlying the trigger of SCDs. EADs were rarely observed under current experimental conditions of a retrogradely perfused isolated heart preparation. Several groups used different conditions in drug-induced LQT rabbit models to trigger EADs, including bradycardia by $\mathrm{AV}$ node ablation, low $\mathrm{K}^{+}, \mathrm{low} \mathrm{Mg}^{2+}$, and adrenergic stimulation by $\alpha$ and/or $\beta$ agonists (49-51). Further studies are required to verify that these conditions can induce EADs in the transgenic model of LQT and to investigate mechanisms of EADs and their preferential locations, such as Purkinje or M cells.

In pharmacological rabbit models of LQTS2, abnormal calcium release from the sarcoplasmic reticulum was shown to cause EADs and trigger polymorphic VT in accordance with the hypothesis 
that Ca overload may underlie these arrhythmias (44). The involvement of abnormal $\mathrm{Ca}^{2+}$ handling in transgenic LQT2 rabbits is the subject of ongoing investigations.

Rabbit $I_{K r}$ and $I_{K s}$ are regionally differentially expressed, causing regional APD differences after pharmacological block (52). Recently, rabbits with AV-block and tachycardic or bradycardic pacing were found to have QT prolongation due to differential downregulation of repolarizing $\mathrm{K}^{+}$currents (53), which leads to differential susceptibility for ventricular arrhythmias: whereas the combined reduction of $I_{K s}$ and $I_{K r}$ was proarrhythmic, the downregulation of $I_{K s}$ alone was not. Additional pharmacological block of $I_{K r}$ using dofetilide caused polymorphic VT and death in these animals, suggesting a crucial role of $I_{K r}$ in the genesis of arrhythmias in these rabbits. This supports our finding that the transgenic elimination of $I_{K s}$ alone in LQT1 does not result in spontaneous arrhythmias, whereas the elimination of $I_{K r}$ leads to spontaneous arrhythmias and sudden death in LQT2 rabbits.

Cellular electrophysiology studies also showed that the pore mutants specifically eliminated the targeted currents $\left(I_{K s}\right.$ in LQT1 cells and $I_{K r}$ in LQT2 rabbits). In addition, we observed a remodeling effect associated with downregulation of the second major repolarizing currents. Thus, $I_{K r}$ is downregulated in LQT1 rabbits, whereas $I_{K s}$ is reduced in LQT2 rabbits. These effects were channel specific, as the expression of either $I_{t o}$ or $I_{K 1}$ was unchanged. Pulldown experiments in our laboratory confirmed weak interactions between KCNQ1 and KCNH2 polypeptides and also confirmed that a small fraction of these peptides could be coprecipitated in transient cotransfection experiments in $\mathrm{CHO}$ cells, similar to previously published studies (54). The lack of change in the steady state level of these polypeptides suggests that abnormal processing or trafficking to the membrane underlies the reduction in the density of these currents. Taken together, these observations support the possibility that KCNH2 and KvLQT1 polypeptides interact directly (or indirectly) in vivo and that a mutation of either of these channels could have a dominant negative effect on the other's currents. These phenomena can explain the severe clinical phenotype of the pore mutants in some LQTS patients $(36,55)$. We propose that genetic models such as LQT2 rabbits may help identify mechanisms of sudden cardiac death, while LQT1 rabbits may serve as a sensitive assay system for detecting effects of drugs on HERG in vivo.

Limitations. As with every transgenic model, results obtained in 1 species do not necessarily transfer into other species, even though these models resemble the human phenotype of LQTS1 and LQTS2 more than any of the previously available models. Additionally, we cannot exclude a nonspecific effect of the presence of the transgene per se, as due to financial constraints, we did not create transgenic control rabbits with an inert gene.

\section{Methods}

All animal studies were performed in accordance with the local guidelines of the institutions and only after approval by the Institutional Animal Care and Use Committee of Pennsylvania State University College of Medicine and the Milton S. Hershey Medical Center, Hershey, Pennsylvania, USA, and the Institutional Animal Care and Use Committee of Rhode Island Hospital, Providence, Rhode Island, USA, in accordance with the NIH Guide for the Care and Use of Laboratory Animals (NIH publication no. 85-23. Revised 1996).

Transgene construct. We obtained the well-characterized clone KvLQT1Y315S from J. Barhanin (21) and the well-studied mutant HERG-G628S from M.C. Sanguinetti (5). The rabbit $\beta$-MyHC promoter was obtained from the J. Robbins laboratory (22). The rabbit $\beta$-MyHC promoter construct (10 kb; in pBlueScript II SK vector) was linearized with EcoRI as the cloning site. The $-\mathrm{PO}_{4}$ ends of the promoter-vector construct were removed, and the purified PCR-generated $\mathrm{K}^{+}$channel cDNAs were ligated to it. The recombinants were identified both by colony PCR and restriction analysis. The error-free $\beta$-MyHC-FLAG-KvLQT1-Y315S (LQTS1) and $\beta$-MyHC-FLAG-HERG-G628S (LQTS2) constructs were used for injection into NZW rabbit embryos and implanted into foster mothers. Female NZW rabbits were used as embryo donors after being injected i.v. with $120 \mathrm{U}$ of pregnant mare serum gonadotropin (PMSG) and $150 \mathrm{U}$ of human chorionic gonadotropin (hCG) on day 1 and day 4 , respectively. The rabbits were then mated with a fertile male on day 4 immediately prior to the hCG injection. The recipient rabbits were mated with a vasectomized male at the same time point as the donor rabbits. Embryos at single-cell stage were harvested on day 5 , injected with the transgene construct, and transplanted to the oviducts of anesthetized recipient rabbits via laparotomy. The entire procedure was performed while the animals were under appropriate anesthesia and by the standard aseptic procedures. A total of 6 batches of embryos (each containing approximately 12-15 fertilized oocytes) were injected and implanted into foster mothers.

The generated offspring were screened with genomic DNA from ear biopsies for the presence of the transgene. The forward primer used for all PCR reactions was derived from the primer used from the $\beta$-MyHC: 5'-GAACCAGCTTCTTCCGCTCACTACAGGTACAG-3'. We used 2 reverse oligonucleotides for HERG: 5'-GGGCACATCCACCAGACATAGGAAGCAG-3' and 5'-CCCACCATGTCCTTCTCCATCACCACCTC-3', with corresponding products of 400 and $487 \mathrm{bp}$. We used a common reverse primer in the human growth hormone polyA signal to detect KvLQT1 transgene: 5'-CTTAATTTTATTAGGACAAGGCTGGTG-3'. The 2 forward oligonucleotides for KvLQT1 were 5'-CACATCACCCAGCCCTGCGGCAGTG - 3 ' and 5'-AAGCCCTCACTGTTCATCTC-3', with corresponding products of 222 and $399 \mathrm{bp}$. Offspring of founders were crossbred with WT NZW rabbits; vertical transmission was confirmed by PCR of the subsequent generations and by ECG analysis.

Southern blot. As a KvLQT1 probe, a 222-bp PCR product was used for LQT1 rabbit genotyping and as a HERG probe, a 400-bp PCR product for LQT2 rabbit genotyping was used. GAPDH cDNA control probe was obtained from Clontech.

Genomic DNA was isolated from rabbit tissue using a standard method. For each genomic Southern blot lane, $12 \mu \mathrm{g}$ of genomic DNA was digested overnight at $37^{\circ} \mathrm{C}$ with $40 \mathrm{U}$ of EcoRI (Promega) in a 50- $\mu$ l reaction with a buffer supplied by the manufacturer. For control lanes, $0.3-3 \mathrm{ng}$ of PCDNA3 HERG or PCDNA3 KvLQT1 plasmid DNA was digested with EcoRI. Digested DNA was electrophoresed on a $0.7 \%$ agarose gel with $1 \times$ Tris-acetate EDTA (TAE) running buffer overnight at $1 \mathrm{~V} / \mathrm{cm}$. The DNA was transferred onto GeneScreen Plus Hybridization Transfer Membrane (NEN Biotechnology System) using a standard capillary method and incubated at least overnight with 1 change of paper towels. The transferred DNA was cross-linked to the membrane with CL-1000 UV crosslinker (UVP Inc.). $25 \mathrm{ng}$ of each probe was labeled with $50 \mu \mathrm{Ci}$ of $\left[\alpha-{ }^{32} \mathrm{P}\right] \mathrm{dCTP}(3000 \mathrm{Ci} / \mathrm{mmol}$; PerkinElmer) using a random primer labeling kit from Stratagene. The membrane was prehybridized for 30 minutes at $60^{\circ} \mathrm{C}$ in ExpressHyb Hybridization Solution (Clontech) and hybridized in the same solution with 1 to $2 \times 10^{7} \mathrm{cpm}$ of each probe for 1 hour at $60^{\circ} \mathrm{C}$. Blots were washed 3 times with $2 \times \mathrm{SSC}+0.05 \%$ SDS at room temperature for 10 minutes each and 2 times with $0.1 \times \mathrm{SSC}+0.1 \% \mathrm{SDS}$ for 20 minutes each at $60^{\circ} \mathrm{C}$. Washed blots were subjected to autoradiography, with exposure time varied from 16 hours to 72 hours. The blots were also visualized with a phosphoimager followed by direct counting of the bands. The rabbit genomic DNAs were cut with EcoRI, and the full length of the respective sections of the transgenes 
that code for KVLQT1-Y315S (2070 bp) and HERG-G628S (3519 bp) were visualized by the indicated probes. The copy number of transgene in the rabbit genome was calculated based on the assumption that the diploid content of a rabbit genome is $7 \times 10^{9} \mathrm{bp}$ (Entrez Genome Project, http:// www.ncbi.nlm.nih.gov/sites/entrez?db=genomeprj\&cmd=Retrieve $\&$ dopt $=$ Overview\&list_uids=12818). Since $12 \mu \mathrm{g}$ of genomic DNA was used for each lane, 1 copy standard is equal to $3519 \times 12 \times 10^{-6} / 7 \times 10^{9}=6.03 \mathrm{pg}$ for the HERG and $2070 \times 12 \times 10^{-6} / 7 \times 10^{9}=3.56 \mathrm{pg}$ for KvLQT1. The intensity of the hybridization band was compared with a corresponding standard containing either 120 pg of HERG cDNA or 83 pg of KvLQT1 cDNA.

Western blots and IP. Membrane preparation protocol was as follows: sections of snap-frozen heart were weighed $(200 \mathrm{mg})$ and homogenized in $1 \mathrm{ml}$ of extraction buffer (50 mM Tris- $\mathrm{HCl}, 150 \mathrm{mM} \mathrm{NaCl}, 1 \mathrm{mM}$ EDTA, and $10 \%$ glycerol) with protease inhibitors (1836153; Roche) (HEB w/pi) using a hand-held polytron. Samples were centrifuged at $4,000 \mathrm{~g}$ for 15 minutes at $4^{\circ} \mathrm{C}$. Supernatants were centrifuged at $100,000 \mathrm{~g}$ for 30 minutes at $4^{\circ} \mathrm{C}$. Resulting pellets were then suspended in $200 \mu \mathrm{l}$ of $\mathrm{HEB} \mathrm{w} / \mathrm{pi}$, aliquotted, and kept frozen at $-80^{\circ} \mathrm{C}$.

The IP protocol was as follows: $150 \mu \mathrm{g}$ membrane protein was brought to $1 \mathrm{ml}$ by adding HEB w/pi and Triton X-100 to a final concentration of $1 \%$ and agitated at $4^{\circ} \mathrm{C}$ for 1 hour. Unsolubilized fraction was removed by centrifugation at $16,000 \mathrm{~g}$ for 30 minutes. Anti-FLAG antibody $(2 \mu \mathrm{l})$ (F-3165; Sigma-Aldrich) was added to the cleared supernatant and agitated at $4^{\circ} \mathrm{C}$ for at least 1 hour. Protein $\mathrm{A} / \mathrm{G}$ plus agarose (SC-2003; Santa Cruz Biotechnology Inc.) was resuspended, and $100 \mu \mathrm{l}$ was added to each IP and incubated again with agitation at $4^{\circ} \mathrm{C}$ for at least 1 hour. Samples were then centrifuged at $700 \mathrm{~g}$ for 1 minute to pellet the beads, after which the supernatant was removed. Beads were washed 3 times with RIPA buffer $(50 \mathrm{mM}$ Tris-HCl, pH 7.4, $150 \mathrm{mM} \mathrm{NaCl}, 1 \% \mathrm{NP}-40,0.5 \%$ sodium deoxycholate, and $0.1 \%$ SDS). Beads were then boiled for 5 minutes in $2 \times$ Laemmli sample buffer (4\% SDS, $20 \%$ glycerol, $100 \mathrm{mM}$ Tris-HCl, $\mathrm{pH} 6.8$, and $0.2 \%$ bromophenol blue) and centrifuged for 2 minutes at $12,000 \mathrm{~g}$ at room temperature. The remaining supernatant was loaded onto an acrylamide gel for SDS-PAGE.

Western blot protocol was as follows: protein samples were boiled at $100^{\circ} \mathrm{C}$ for 5 minutes, then loaded onto an $8 \%$ acrylamide/SDS gel and run at $55 \mathrm{~mA}$ for at least 3 hours. The proteins were then transferred onto nitrocellulose membrane (NBA085C; PerkinElmer) and remained overnight at $54 \mathrm{~V}$ in a $4^{\circ} \mathrm{C}$ chromatography refrigerator. The membrane was stained with Ponceau $\mathrm{S}$ to confirm protein transfer. Blocking was performed on a rocker at room temperature in TBS $/ 5 \%$ milk for 1 hour. Anti-FLAG antibody was diluted at 1:1000 in TBS $/ 5 \%$ milk. The membrane was then incubated in the diluted antibody for at least 1 hour on a rocker at room temperature. Washes were performed with TBS/0.5\% Tween 3 times for at least 5 minutes. HRP-conjugated goat anti-mouse (62-6420; Invitrogen) was diluted in $\mathrm{TBS} / 5 \%$ milk at a concentration of 1:10,000. The membrane was incubated in the secondary antibody on a rocker at room temperature for at least 1 hour. The membrane was then washed again 3 times in TBS/ $0.5 \%$ Tween. After a brief rinse in TBS, the membrane was incubated in chemiluminescent substrate (34080; Pierce Biotechnology) for 1 minute and exposed to $\mathrm{x}$-ray film for detection. Antibodies used for ion channels were anti-HERG (APC-062; Alomone Labs) and anti-KCNQ1 (APC-022; Alomone Labs).

Telemetric monitoring. For monitoring of awake, free-moving, unrestrained rabbits, we used implantable radiofrequency ECG transmitters (triple-lead ECG F70-EEE; Data Sciences International). To implant the transmitters, we anesthetized animals with i.m. ketamine/xylazine $(25 / 3.75 \mathrm{mg} / \mathrm{kg}$ $\mathrm{BW})$, buprenorphine $(0.03 \mathrm{mg} / \mathrm{kg})$, and inhaled isoflurane $(0.5 \%-5 \%)$. The implantable device was placed s.c. on an the animal's back through a small incision. Pairs of electrodes were tunnelled s.c. to the right and left shoulder and the left and right hips, and then secured with a suture to the muscle. The derived ECG corresponds to standard ECG limb leads I-III. The analog telemetric signals were digitized at $1 \mathrm{kHz}$, and the data were acquired by a Microsoft Windows-based Dataquest A.R.T. data acquisition software (Data Sciences International). ECG recordings were performed at least 3 weeks after transmitter implantation to allow for full recovery of the animals.

The ECG data were analyzed offline in a blinded fashion, and PR, QT, QT peak, JT, QRS, and RR intervals were measured with Ponemah ECG analysis software (Data Sciences International). Every 20 minutes during the 24-hour recording, average values were measured onscreen. Spontaneous arrhythmic events were analyzed by semiautomatic screening of the digital recordings for abrupt changes in the RR intervals and subsequently confirmed by an experienced clinical electrophysiologist.

Echocardiographic studies. Transthoracic echocardiography was performed in sedated animals (ketamine/xylazine) to exclude an effect of the transgene on ventricular dimensions and contractility; a $7.5-\mathrm{mHz}$ probe and long axis and short axis views were used. Analysis included dimensions of the $\mathrm{LV}$ and RV, left atrium, wall thickness, valve function, and LV ejection fraction (calculated using Teichholz's formula) and was performed by an experienced echocardiographer blinded to the genotype.

Preparation of rabbit ventricular myocytes. Ventricular myocytes were isolated from the hearts of transgenic and LMC NZW rabbits (males, 3.4-5.4 kg) with standard enzymatic techniques. The heart was removed from euthanized rabbits and perfused for 5 to 7 minutes with a nominally calcium-free solution containing $130 \mathrm{mM} \mathrm{NaCl}, 5.4 \mathrm{mM} \mathrm{KCl}, 1.5 \mathrm{mM} \mathrm{MgCl}_{2}$, $0.33 \mathrm{mM} \mathrm{NaH}_{2} \mathrm{PO}_{4}, 8 \mathrm{mM}$ taurine, $5 \mathrm{mM}$ HEPES, $5 \mathrm{mM}$ pyruvic acid, and $5 \mathrm{mM}$ glucose. Subsequently, the heart was perfused for 10 to 15 minutes with the same solution to which $0.075 \%$ collagenase (type 1 ; Worthington Biochemical), 20 to $40 \mu \mathrm{M} \mathrm{CaCl}_{2}$, and $0.1 \% \mathrm{BSA}$ were added. The apical of $\mathrm{LV}$ was cut off and minced, and the cells were dispersed with a glass pipette for 3 to 5 minutes in a solution containing $45 \mathrm{mM} \mathrm{KCl}, 70 \mathrm{mM} \mathrm{K}$-glutamate, $3 \mathrm{mM} \mathrm{MgSO}_{4}, 15 \mathrm{mM} \mathrm{KH}_{2} \mathrm{PO}_{4}, 16 \mathrm{mM}$ taurine, $10 \mathrm{mM}$ HEPES, $0.5 \mathrm{mM}$ EGTA, and $10 \mathrm{mM}$ glucose (pH 7.38). The cell suspension was filtered through a $100-\mu \mathrm{m}$ nylon mesh, kept at room temperature for 1 hour before transfer to MEM containing $1 \mathrm{mM} \mathrm{Ca}^{2+}$, and used within 6 to 8 hours.

Electrophysiological recording and data analysis. Whole-cell recordings were obtained with an Axopatch-200B amplifier (Axon Instruments) with standard patch-clamp techniques. Tyrode solution was used as a standard bath solution and contained $140 \mathrm{mM} \mathrm{NaCl}, 5.4 \mathrm{mM} \mathrm{KCl}, 0.33 \mathrm{mM} \mathrm{NaH}_{2} \mathrm{PO}_{4}$, $1 \mathrm{mM} \mathrm{MgCl}_{2}, 1 \mathrm{mM} \mathrm{CaCl}_{2}, 5 \mathrm{mM}$ HEPES, and $7.5 \mathrm{mM}$ glucose, $\mathrm{pH}$ 7.4. The pipette resistances were 2 to $4 \mathrm{M} \Omega$ when filled with $120 \mathrm{mM} \mathrm{KCl}, 5 \mathrm{mM}$ $\mathrm{MgCl}_{2}, 0.36 \mathrm{mM} \mathrm{CaCl}_{2}, 5 \mathrm{mM}$ EGTA, $5 \mathrm{mM}$ HEPES, $5 \mathrm{mM}$ glucose, $5 \mathrm{mM}$ $\mathrm{K}_{2}$-ATP, $5 \mathrm{mM} \mathrm{Na} 2-\mathrm{CrP}, 0.25 \mathrm{mM} \mathrm{Na}-\mathrm{GTP}$, pH adjusted 7.2 with potassium hydroxide $(\mathrm{KOH})$. Action potential and currents were recorded at approximately $32^{\circ} \mathrm{C}$, and action potentials were recorded at a stimulation rate of $0.1 \mathrm{~Hz}$. Capacitance and $60 \%$ to $80 \%$ of series resistance were routinely compensated. The sampling frequency was $2.5 \mathrm{kHz}$; the $-3 \mathrm{~dB}$ cut-off frequency was $1 \mathrm{kHz}$. Action potential, $I_{t o}$, and $I_{K 1}$ were recorded in Tyrode solution, while $I_{K r}$ and $I_{K s}$ were recorded in low $\mathrm{K}^{+}$and low divalent cation solution containing $140 \mathrm{mM} \mathrm{NaCl}, 1.5 \mathrm{mM} \mathrm{KCl}, 0.33 \mathrm{mM} \mathrm{NaH}_{2} \mathrm{PO}_{4}, 0.2 \mathrm{mM} \mathrm{MgCl}_{2}$, $0.2 \mathrm{mM} \mathrm{CaCl}_{2}, 0.2 \mathrm{mM} \mathrm{CdCl}_{2}, 5 \mathrm{mM}$ HEPES, and $7.5 \mathrm{mM}$ glucose, $\mathrm{pH} 7.4$. Action potential was recorded under current clamp, holding at 0 ; pulses were $3 \mathrm{~ms}$ in duration, 1.2-fold the threshold intensity, and at a stimulation rate of $0.1 \mathrm{~Hz}$. For $I_{K r}$ and $I_{K s}$ recording, holding potential was at $-40 \mathrm{mV}$, test potentials were from -30 to $+30 \mathrm{mV}$ with steps of $10 \mathrm{mV}$ lasting 3 seconds. Tail current was recorded after the test potential was back to $-40 \mathrm{mV}$. For $I_{t o}$ recording, holding potential was at $-80 \mathrm{mV}$ and test potentials were from -20 to $+50 \mathrm{mV}$ with steps of $10 \mathrm{mV}$ lasting $400 \mathrm{~ms}$. For $I_{K 1}$ recording, a 2-second ramp from $-120 \mathrm{mV}$ to $+60 \mathrm{mV}$ was used as stimulation voltage.

E-4031 and chromanol 293B were used for isolating $I_{K r}$ and $I_{K s}$. Tetrodotoxin (TTX) $(20 \mu \mathrm{M})$ and $\mathrm{CdCl}_{2}(0.2 \mathrm{mM})$ were added as needed to block sodium and calcium currents. A stock solution of E-4031 (5 mM) was 
prepared in water; chromanol 293B $(30 \mathrm{mM})$ in DMSO; TTX $(20 \mathrm{mM})$ in sodium acetate and acetate acid buffer. All stock solutions were stored at $-20^{\circ} \mathrm{C}$. Before the experiment, the stock solution was diluted in the external solution to the desired concentrations.

Optical mapping methods: isolated heart preparation. LMC and transgenic rabbits (either sex, $3.5 \sim 5.5 \mathrm{~kg}$ ) were injected with buprenorphene $(0.03 \mathrm{mg} / \mathrm{kg}$, i.m.), acepromazine $(0.5 \mathrm{mg} / \mathrm{kg}$, i.m.), xylazine $(15 \mathrm{mg} / \mathrm{kg}$, i.m.), ketamine $(60 \mathrm{mg} / \mathrm{kg}$, i.m.), and pentothal ( $35 \mathrm{mg} / \mathrm{kg}$, i.v.) plus heparin $(200 \mathrm{U} / \mathrm{kg})$. The heart was excised and retrogradely perfused through the aorta with $130 \mathrm{mM} \mathrm{NaCl}, 24 \mathrm{mM} \mathrm{NaHCO}_{3}, 1.0 \mathrm{mM} \mathrm{MgCl}_{2}, 4.0 \mathrm{mM} \mathrm{KCl}$, $1.2 \mathrm{mM} \mathrm{NaH}_{2} \mathrm{PO}_{4}, 5 \mathrm{mM}$ dextrose, $20 \mathrm{mM}$ mannitol, and $1.0 \sim 1.25 \mathrm{mM}$ $\mathrm{CaCl}_{2}, \mathrm{pH} 7.4$, and gassed with $95 \% \mathrm{O}_{2}$ and $5 \% \mathrm{CO}_{2}$. In total, 16 rabbits were studied: LMC $(n=7)$, LQT1 $(n=4)$, and LQT2 $(n=5)$. One LQT2 rabbit exhibited substantially longer APD and was not able to be paced at fast-cycle length; it was excluded from the data analysis. To compare the mechanism of arrhythmias in LQT2 with long QT phenotype and lack thereof in LQT1 rabbits with long QT phenotype, we compared the optical mapping data of LQT2 rabbits with that of LQT1 rabbits with a QT index in their surface ECG equal to or greater than $100 \%$. LQT1 rabbits with a QT index of less than $95 \%$ were excluded from the optical mapping studies. Temperature was maintained at $37.0 \pm 0.2^{\circ} \mathrm{C}$, and perfusion pressure was adjusted to approximately $60 \mathrm{~mm} \mathrm{Hg}$ with a peristaltic pump (Radnoti Glass Technology). Hearts were stained with a voltage-sensitive dye, di-4 ANEPPS (Invitrogen), $25 \mu \mathrm{l}$ of stock solution $(1 \mathrm{mg} / \mathrm{ml}$ of die dissolved in dimethyl sulfoxide, DMSO) delivered through the bubble trap, above the aortic cannula. ECGs and perfusion pressure were continuously monitored (PowerLab; ADInstruments). Hearts were placed in a chamber to maintain temperature, and $5 \mu \mathrm{M}$ blebbistatin was added to the perfusate to reduce movement artifacts (56). Hearts were stimulated at basic cycle lengths of $350 \mathrm{~ms}$ and $300 \mathrm{~ms}$ from the LV epicardial base region and subsequently stimulated at progressively shorter cycle lengths (10 ms decrement) until 2:1 capture was seen or ventricular arrhythmia was induced.

Optical mapping. The optical apparatus was previously described (57). Fluorescence images from the anterior surface of the heart were focused on a CMOS camera $(100 \times 100$ pixels; Ultima-L), and the field of view was set to $1.5 \times 1.5 \mathrm{~cm}^{2}$ with a spatial resolution of $150 \times 150 \mu \mathrm{m}^{2}$. Sampling rate was set to $1000 \mathrm{f} / \mathrm{s}$, and data were analyzed with custom-built software using Interactive Data Language (ITT Visual Information Solutions). Activation and repolarization time points at each site were determined from $(d F / d t)_{\max }$ (the maximum instantaneous change of fluorescence during action potential upstroke) and $\left(d^{2} F / d t^{2}\right)_{\max }$, which was shown to coincide with approximately $97 \%$ repolarization to baseline and recovery from refractoriness (58). Data were filtered using a spatial Gaussian filter $(3 \times 3$ pixels $)$, and first/second derivatives $\left(d F / d t, d^{2} F / d t^{2}\right)$ were calculated using a polynomial filter (third order, 13 points). Pixels with low signal-to-noise ratios determined by $(d F / d t)_{\max }$ (lower than $3 \times \mathrm{SD}$ of baseline), and outliers of pixels determined by Grubbs' test were removed from the analysis (typically less than $1 \%$ of total pixels).

Statistics. Tests for normal distribution used the D'Agostino and Pearson omnibus normality or the Kolmogorov-Smirnov test. For normally distributed values, Student's $t$ test (paired and unpaired) was used to compare the means of 2 groups, and Mann-Whitney and Wilcoxon matchedpairs test was used for values not normally distributed. Fisher's exact test was used for categorical variables. For comparisons of more than 2 groups, ANOVA (parametric and nonparametric) with Newman-Keuls or Dunn's post-test was used. Survival analysis was performed according to the Kaplan-Meier method; survival proportions were compared with the log-rank test. Cellular electrophysiology data were evaluated using pClamp 9.0 and Origin 7.0 software, and results are given as mean \pm SEM. All other analyses were performed with Prism 4.03 for Windows (Graph$\mathrm{Pad}$ ) or SPSS for Windows, and their data are presented as means \pm SD; $n$ indicates the number of experiments/animals, tests were 2 -tailed, and $P<0.05$ was considered significant.

\section{Acknowledgments}

The authors thank J. Barhanin and M.C. Sanguinetti for the KvLQT1-Y315S and HERG-G628S clones, respectively, and $\mathrm{J}$. Robbins for the rabbit $\beta$-MyHC promoter cDNA. The authors wish to thank Max Lang for his support of the project. G. Koren is a recipient of NIH grant RO1 HL046005-14; M. Brunner and $\mathrm{K}$. Odening were supported in part by grants from the German Cardiac Society (Max Schaldach and St. Jude Medical Stipendium). The authors thank Jun Zhou for his valuable comments in reviewing the manuscript.

Received for publication August 13, 2007, and accepted in revised form March 19, 2008.

Address correspondence to: Gideon Koren, Cardiovascular Research Center, Cardiology Division, Rhode Island Hospital, Coro West 51031 Hoppin Street, Providence, Rhode Island 02903, USA. Phone: (401) 444-0392; Fax: (401) 444-4061; E-mail: Gideon_Koren@Brown.edu.

Michael Brunner, Xuwen Peng, and Gong Xin Liu contributed equally to this work.
1. Moss, A.J. 2003. Long QT syndrome. JAMA. 289:2041-2044.

2. Priori, S.G., Bloise, R., and Crotti, L. 2001. The long QT syndrome. Europace. 3:16-27.

3. Roden, D.M. 2008. Long-QT syndrome. N. Engl. J. Med. 358:169-176.

4. Curran, M.E., et al. 1995. A molecular basis for cardiac arrhythmia: HERG mutations cause long QT syndrome. Cell. 80:795-803.

5. Sanguinetti, M.C., Curran, M.E., Spector, P.S., and Keating, M.T. 1996. Spectrum of HERG K+-channel dysfunction in an inherited cardiac arrhythmia. Proc. Natl. Acad. Sci. U. S. A. 93:2208-2212.

6. Sanguinetti, M.C., et al. 1996. Coassembly of K (V)LQT1 and minK (IsK) proteins to form cardiac I (Ks) potassium channel. Nature. 384:80-83.

7. Sanguinetti, M.C., Jiang, C., Curran, M.E., and Keating, M.T. 1995. A mechanistic link between an inherited and an acquired cardiac arrhythmia: HERG encodes the IKr potassium channel. Cell. 81:299-307.
8. Seth, R., etal.2007. LongQT syndrome and pregnancy. J. Am. Coll. Cardiol. 49:1092-1098.

9. Sauer, A.J., et al. 2007. Long QT syndrome in adults. J. Am. Coll. Cardiol. 49:329-337.

10. Jeron, A., et al. 2000. Inducible polymorphic ventricular tachyarrhythmias in a transgenic mouse model with a long Q-T phenotype. Am. J. Physiol. Heart Circ. Physiol. 278:H1891-H1898.

11. Guo, W., Li, H., London, B., and Nerbonne, J.M. 2000. Functional consequences of elimination of $\mathrm{i}$ (to,f) and i (to,s): early afterdepolarizations, atrioventricular block, and ventricular arrhythmias in mice lacking Kv1.4 and expressing a dominantnegative Kv4 alpha subunit. Circ. Res. 87:73-79.

12. Demolombe, S., et al. 2001. Transgenic mice overexpressing human KvLQT1 dominant-negative isoform. Part I: Phenotypic characterisation. Cardiovasc. Res. 50:314-327.

13. Brunner, M., et al. 2001. Characterization of mice with a combined suppression of I (to) and I (K,slow). Am. J. Physiol. Heart Circ. Physiol. 281:H1201-H1209.
14. Guo, W., et al. 2005. Targeted deletion of Kv4.2 eliminates I (to,f) and results in electrical and molecular remodeling, with no evidence of ventricular hypertrophy or myocardial dysfunction. Circ. Res. 97:1342-1350.

15. London, B., et al. 1998. Long QT and ventricular arrhythmias in transgenic mice expressing the $\mathrm{N}$ terminus and first transmembrane segment of a voltage-gated potassium channel. Proc. Natl. Acad. Sci. U. S. A. 95:2926-2931.

16. Zhou, J., et al. 2003. Regional upregulation of Kv2.1-encoded current, IK,slow2, in Kv1DN mice is abolished by crossbreeding with $\mathrm{Kv} 2 \mathrm{DN}$ mice. Am. J. Physiol. Heart Circ. Physiol. 284:H491-H500.

17. Baker, L.C., London, B., Choi, B.R., Koren, G., and Salama, G. 2000. Enhanced dispersion of repolarization and refractoriness in transgenic mouse hearts promotes reentrant ventricular tachycardia. Circ. Res. 86:396-407.

18. Nerbonne, J.M., Nichols, C.G., Schwarz, T.L., and Escande, D. 2001. Genetic manipulation of car- 
diac $\mathrm{K}(+)$ channel function in mice: what have we learned, and where do we go from here? Circ. Res. 89:944-956.

19. Nerbonne, J.M. 2004. Studying cardiac arrhythmias in the mouse - a reasonable model for probing mechanisms? Trends Cardiovasc. Med. 14:83-93.

20. Vermeulen, J.T., et al. 1994. Triggered activity and automaticity in ventricular trabeculae of failing human and rabbit hearts. Cardiovasc. Res. 28: $1547-1554$

21. Chouabe, C., et al. 1997. Properties of KvLQT1 K+ channel mutations in Romano-Ward and Jervell and Lange-Nielsen inherited cardiac arrhythmias. EMBO J. 16:5472-5479.

22. James, J., et al. 2000. Transgenic modeling of a cardiac troponin I mutation linked to familial hypertrophic cardiomyopathy. Circ. Res. 87:805-811.

23. Bhandari, A.K., et al. 1985. Electrophysiologic testing in patients with the long QT syndrome. Circulation. 71:63-71.

24. Ackerman, M.J., et al. 2002. Epinephrine-induced QT interval prolongation: a gene-specific paradoxical response in congenital long QT syndrome. Mayo Clin. Proc. 77:413-421.

25. Noda, T., et al. 2002. Gene-specific response of dynamic ventricular repolarization to sympathetic stimulation in LQT1, LQT2 and LQT3 forms of congenital long QT syndrome. Eur. Heart J. 23:975-983.

26. Shimizu, W., and Kamakura, S. 2001. Catecholamines in children with congenital long QT syndrome and Brugada syndrome. J. Electrocardiol. 34(Suppl.):173-175.

27. Suzuki, A., Bosnjak, Z.J., and Kwok, W.M. 2003. The effects of isoflurane on the cardiac slowly activating delayed-rectifier potassium channel in Guinea pig ventricular myocytes. Anesth. Analg. 96:1308-1315.

28. Viskin, S., et al. 1996. Mode of onset of torsade de pointes in congenital long QT syndrome. J. Am. Coll. Cardiol. 28:1262-1268.

29. Panfilov, A.V. 2006. Is heart size a factor in ventricular fibrillation? Or how close are rabbit and human hearts? Heart Rhythm. 3:862-864.

30. James, J., et al. 2000. Genetic manipulation of the rabbit heart via transgenesis. Circulation. 101:1715-1721.

31. Malik, M., et al. 2002. Relation between QT and RR intervals is highly individual among healthy subjects: implications for heart rate correction of the QT interval. Heart. 87:220-228.

32. Nemec, J., et al. 2004. Heart rate dependence of the QT interval duration: differences among congenital long QT syndrome subtypes. J. Cardiovasc. Elec- trophysiol. 15:550-556.

33. Swan, H., et al. 1999. Sinus node function and ventricular repolarization during exercise stress test in long QT syndrome patients with KvLQT1 and HERG potassium channel defects. J. Am. Coll. Cardiol. 34:823-829.

34. Viitasalo, M., et al. 2002. Differentiation between LQT1 and LQT2 patients and unaffected subjects using 24-hour electrocardiographic recordings. Am. J. Cardiol. 89:679-685.

35. Hobbs, J.B., et al. 2006. Risk of aborted cardiac arrest or sudden cardiac death during adolescence in the long-QT syndrome. JAMA. 296:1249-1254.

36. Moss, A.J., et al. 2002. Increased risk of arrhythmic events in long-QT syndrome with mutations in the pore region of the human ether-a-go-go-related gene potassium channel. Circulation. 105:794-799.

37. Antzelevitch, C. 2007. Ionic, molecular, and cellular bases of QT-interval prolongation and torsade de pointes. Europace. 9(Suppl. 4):iv4-iv15.

38. Antzelevitch, C. 2007. Role of spatial dispersion of repolarization in inherited and acquired sudden cardiac death syndromes. Am. J. Physiol. Heart Circ. Physiol. 293:H2024-H2038.

39. London, B., et al. 2007. Dispersion of repolarization and refractoriness are determinants of arrhythmia phenotype in transgenic mice with long QT. J. Physiol. 578:115-129.

40. Antzelevitch, C., and Shimizu, W. 2002. Cellular mechanisms underlying the long QT syndrome. Curr. Opin. Cardiol. 17:43-51.

41. Shimizu, W., and Antzelevitch, C. 1999. Differential response of transmural dispersion of repolarization and torsade de pointes to beta-adrenergic agonists and antagonists in three models of the long QT syndrome. J. Electrocardiol. 32(Suppl.): 150.

42. Shimizu, W., and Antzelevitch, C. 2000. Differential effects of beta-adrenergic agonists and antagonists in LQT1, LQT2 and LQT3 models of the long QT syndrome. J. Am. Coll. Cardiol 35:778-786.

43. Yan, G.X., et al. 2001. Phase 2 early afterdepolarization as a trigger of polymorphic ventricular tachycardia in acquired long-QT syndrome: direct evidence from intracellular recordings in the intact left ventricular wall. Circulation. 103:2851-2856.

44. Choi, B.R., Burton, F., and Salama, G. 2002. Cytosolic Ca2 + triggers early afterdepolarizations and Torsade de Pointes in rabbit hearts with type 2 long QT syndrome. J. Physiol. 543:615-631.

45. Yinbin, J., Lin, Y., Hong, Z., Yecho, H., and Dazong, J. 2005. Mechanism of reentry trigged by EADs in long-QT syndrome: a simulation study. Conf. Proc. IEEE Eng. Med. Biol. Soc. 7:7068-7071.
46. Viswanathan, P.C., and Rudy, Y.2000. Cellular arrhythmogenic effects of congenital and acquired longQT syndrome in the heterogeneous myocardium. Circulation. 101:1192-1198.

47. Shimizu, W., et al. 1991. Early afterdepolarizations induced by isoproterenol in patients with congenital long QT syndrome. Circulation. 84:1915-1923.

48. Noda, T., et al. 2004. Classification and mechanism of Torsade de Pointes initiation in patients with congenital long QT syndrome. Eur. Heart J. 25:2149-2154.

49. Carlsson, L., et al. 1993. Proarrhythmic effects of the class III agent almokalant: importance of infusion rate, QT dispersion, and early afterdepolarisations. Cardiovasc. Res. 27:2186-2193.

50. Carlsson, L., Abrahamsson, C., Drews, L., and Duker, G. 1992. Antiarrhythmic effects of potassium channel openers in rhythm abnormalities related to delayed repolarization. Circulation. 85:1491-1500.

51. Zabel, M., et al. 1997. Electrophysiologic features of torsades de pointes: insights from a new isolated rabbit heart model. J. Cardiovasc. Electrophysiol. 8:1148-1158.

52. Cheng, J., et al. 1999. Heterogeneous distribution of the two components of delayed rectifier $\mathrm{K}+$ current: a potential mechanism of the proarrhythmic effects of methanesulfonanilideclass III agents. Cardiovasc. Res. 43:135-147.

53. Tsuji, Y., Zicha, S., Qi, X.Y., Kodama, I., and Nattel, S. 2006. Potassium channel subunit remodeling in rabbits exposed to long-term bradycardia or tachycardia: discrete arrhythmogenic consequences related to differential delayed-rectifier changes. Circulation. 113:345-355.

54. Ehrlich, J.R., et al. 2004. KvLQT1 modulates the distribution and biophysical properties of HERG. A novel alpha-subunit interaction between delayed rectifier currents. J. Biol. Chem. 279:1233-1241.

55. Moss, A.J., et al. 2007. Clinical aspects of type-1 long-QT syndrome by location, coding type, and biophysical function of mutations involving the KCNQ1 gene. Circulation. 115:2481-2489.

56. Fedorov, V.V., et al. 2007. Application of blebbistatin as an excitation-contraction uncoupler for electrophysiologic study of rat and rabbit hearts. Heart Rhythm. 4:619-626.

57. Choi, B.R., Jang, W., and Salama, G. 2007. Spatially discordant voltage alternans cause wavebreaks in ventricular fibrillation. Heart Rhythm. 4:1057-1068.

58. Efimov, I.R., Huang, D.T., Rendt, J.M., and Salama, G. 1994. Optical mapping of repolarization and refractoriness from intact hearts. Circulation. 90:1469-1480. 